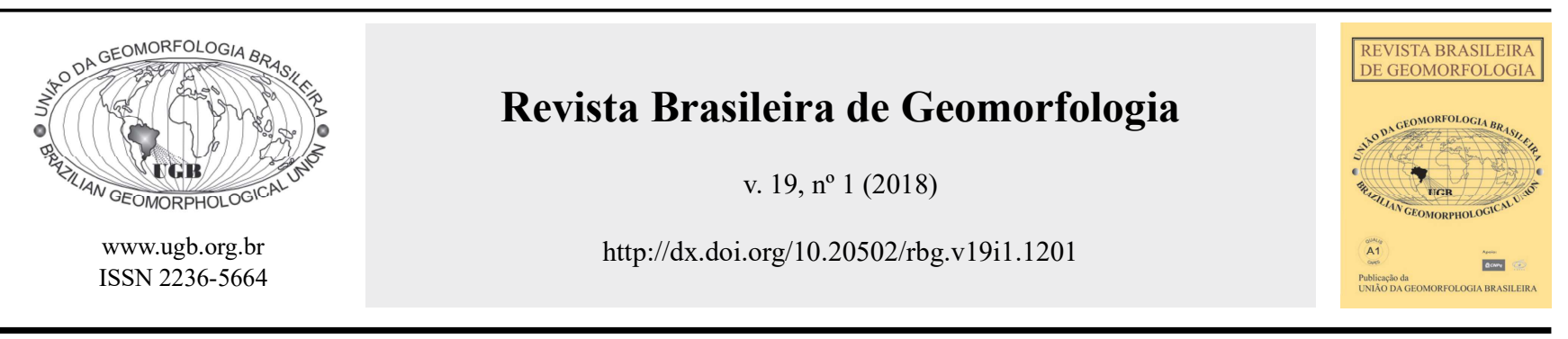

\title{
PROCESSOS, AMBIENTES DEPOSICIONAIS E GEOCRONOLOGIAS DAS COBERTURAS SUPERFICIAIS SOBRE APLAINAMENTOS NEOGÊNICOS E TERRAÇOS FLUVIAIS NA BACIA DO RIBEIRÃO ARAQUÁ, DEPRESSÃO PERIFÉRICA PAULISTA
}

\author{
PROCESSES, DEPOSITIONAL ENVIRONMENTS AND \\ GEOCRONOLOGY OF SURFACE COVERAGES ON NEOGENE \\ LANDFORMS AND FLUVIAL TERRACES IN ARAQUÁ WATERSHED, \\ PAULISTA PERIPHERAL DEPRESSION
}

\author{
André de Oliveira Souza \\ Instituto de Geociências, Universidade Estadual de Campinas \\ R. João Pandiá Calógeras, 51, Campinas, São Paulo. CEP: 13083-870. Brasil
}

Email: andreosouza@ige.unicamp.br

Archimedes Perez, Filho

Instituto de Geociências, Universidade Estadual de Campinas R. João Pandiá Calógeras, 51, Campinas, São Paulo. CEP: 13083-870. Brasil

Email:archi@ige.unicamp.br

\begin{tabular}{l} 
Informações sobre o Artigo \\
Recebido (Received): \\
06/07/2017 \\
Aceito (Accepted): \\
22/10/2017 \\
\hline
\end{tabular}

Palavras-chave:

Dinâmica Geomorfológica; Pulsos Climáticos; Quaternário; LOE.

\section{Keywords:}

Surface Coverage; Climate Pulses; Quaternary; OSL.

\section{Resumo:}

A complexa interpretação da dinâmica geomorfológica quaternária atuante na Depressão Periférica Paulista está relacionada tanto à sutil dinâmica neotectônica quanto à intensidade do intemperismo de regiões tropicais úmidas. Assim, as análises das coberturas superficiais podem subsidiar qualitativamente e quantitativamente a compreensão dos eventos ambientais ocorridos ao longo do Quaternário. Nesse contexto, propõe-se correlacionar a geocronologia dos processos erosivos-deposicionais - responsáveis pela espacialização de coberturas superficiais sobrepostas às superfícies geomorfológicas na bacia hidrográfica do Ribeirão Araquá - a eventos climáticos quaternários. A área estudada localizase na Depressão Periférica Paulista e tem associada à sua dinâmica, Superfícies de Aplainamentos Neogênicas e terraços fluviais pleistocênicos e holocênicos. A fim de estabelecer as características ambientais e geocronologia dos eventos erosivos-deposicionais, realizamos datações por Luminescência Opticamente Estimulada (LOE), análises granulométricas e morfoscópicas. Constatou-se que o recobrimento Quaternário destas formas geomórficas estão vinculados a processos erosivos-deposicionais resultantes de reativações neotectônicas e mudanças climáticas pleistocênicas, bem como ciclos climáticos holocênicos de curta duração (pulsações climáticas). 


\begin{abstract}
:
The complex interpretation of the Quaternary geomorphological dynamics in the Paulista Peripheral Depression is related to both the neotectonic dynamics and the intensity of weathering of the humid tropical regions. Therefore, the analysis of the surface coverages might support qualitatively and quantitatively the understanding of the environmental events that have occurred during the Quaternary. In this context, we propose to correlate the geochronology of the erosive-depositional processes - responsible for the spacialization of surface coverings over the landforms in the Araquá river basin - with Quaternary climatic events. The studied area is in the Paulista Peripheral Depression whose dynamics comprises Neogene Surfaces, Pleistocene and Holocene Fluvial Terraces. In order to establish the environments features and the geochronology of erosive-depositional events, we perform Optical Stimulated Luminescence (OSL) dating, size grain and morphoscopic analysis. The main findings suggest that the Quaternary overlay of these geomorphic forms are associated with erosive-depositional processes, resulting from neotectonic reactivations and Pleistocene climatic changes, as well as short-term Holocene climatic cycles (climate pulsations).
\end{abstract}

\section{Introdução}

A questão cronológica que abarca o desenvolvimento do relevo, tem sido um dos pilares importantes no desenvolvimento da ciência geomorfológica, conduzindo à construção de diversas concepções teóricasmetodológicas (Bishop, 2007). Na Geomorfologia clássica, por meio da análise da sequência de aplainamentos em diferentes níveis altimétricos, seria possível determinar a idade relativa dos processos e formas de relevo (Novaes Pinto, 1988; Adams, 1975; Ab'Saber, 1955; 1969; Salgado, 2007; Silva, 2009). De acordo com essa proposta, topos mais elevados seriam registros de aplainamentos mais antigos, enquanto que aqueles topograficamente mais rebaixados estariam vinculados a processos e eventos ambientais mais recentes. A ênfase em aspectos topográficos, sobretudo altimétricos, que essa abordagem está relacionada, pode conduzir a alguns problemas na interpretação cronológica do relevo, principalmente quando desconsiderada possíveis deformações estruturais após a elaboração dessas superfícies.

Com o surgimento de abordagens teóricometodológicas pautadas na integração de informações sobre o material de recobrimento e as formas de relevo (Queiroz Neto, 2001), assim como a democratização de técnicas para datações absolutas, que utilizam a luminescência de materiais cristalinos (Huntley et al. 1985; Sallun et al., 2007; Cordier, 2010); tornouse possível a revisão de algumas concepções sobre a dinâmica geomorfológica e geocronologia dos processos, inclusive relacionadas às Superfícies de Aplainamentos (Corrêa, 2001; Corrêa et al. 2002; Correa e Mendes, 2002; Arruda, 2008). Assim, as coberturas superficiais sobre superfícies de aplainamentos, vertentes, terraços fluviais e planícies de inundação se apresentam como uma importante ferramenta analítica, uma vez que não estão necessariamente vinculadas a hipsometria, permitindo uma compreensão mais precisa dos processos e dinâmicas geomorfológicas de uma área.

Queiroz Neto (2001) destaca que as coberturas superficiais resultam das alterações das rochas por intemperismo e podem ser retrabalhadas sobre vertentes, superfícies de erosão e planícies fluviais. De acordo com Bigarela e Mousinho (1965), Moura e Mello (1991) e Bigarella et al. (2009), esses depósitos apresentam descontinuidades estratigráficas, geralmente identificadas por camadas que se associam às variações de intensidade dos processos erosivos-deposicionais (clima, tectônica e/ou uso do solo). Neste contexto, coberturas localizadas em níveis hipsométricos mais elevados, podem também ser correlatas àquelas presentes em relevos mais rebaixados, indicando uma correlação não-linear entre a hipsometria e a idade do recobrimento sedimentar superficial.

Do mesmo modo, os terraços fluviais também têm sido utilizados como importantes registros de ajustes da paisagem, pois indicam rupturas no limiar de equilíbrio de um determinado sistema fluvial. Em áreas tectonicamente estáveis, essas rupturas podem estar associadas a alterações no nível de base decorrentes de flutuações climáticas e/ou atividades antrópicas, as quais podem resultar em diferentes níveis de terraços com empilhamento de camadas sedimentares (Vandenberghe, 2002).

De modo geral, terraços fluviais são reconhecidos como uma superfície horizontal ou levemente inclinada, modeladas pela erosão fluvial, marinha e/ou lacustre 
(Leopold et al., 1964; Bigarella e Mousinho, 1965; Christofoletti, 1981). Representam, desta forma, antigas superfícies de agradação, que em decorrência de processos climáticos, tectônicos, antropogênicos e autogênicos são abandonadas (Leopold et al., 1964; Bridgland e Westaway, 2008; Vandenberghe, 2015). Assim, os sistemas fluviais representam não apenas uma importante parte do sistema geomorfológico geral, mas também registros sedimentares, morfológicos e ecológicos sobre condições climáticas, processos erosivos-deposicionais e da dinâmica geomorfológica de bacias hidrográficas (Vandenberghe, 2002).

Na bacia hidrográfica do Ribeirão Araquá, diferentes superfícies geomorfológicas recobertas por coberturas superficiais foram estudadas desde a década de 1960 (Bigarella et al.1965; Ab'Saber, 1969; Modenesi, 1974; Penteado, 1968a; Ponçano e Almeida, 1993; Melo, 1995). No âmbito das superfícies de aplainamentos encontradas na área, as gêneses das mesmas estão associadas aos processos de circundenudação que originou a Depressão Periférica Paulista (Ab'Saber, 1955; Pinheiro e Queiroz Neto, 2014), e apresentam coberturas superficiais ainda pouco exploradas sob a óptica geocronológica. Essas superfícies são comumente relacionadas às Superfícies Neogênicas (Penteado, 1968a). No âmbito das superfícies geomorfológicas mais recente, alguns estudos têm demonstrado a existência de níveis de terraços fluviais elaborados após ajustes estruturais na rede drenagem durante o Pleistoceno Médio-Superior e Holoceno (Oppenheim e Malamphy, 1936; Souza e Perez Filho, 2015; Souza e Perez Filho, 2016a).

Deste modo, o objetivo do presente trabalho é delinear a geocronologia absoluta dos processos e ambientes deposicionais responsáveis pela gênese e espacialização de coberturas superficiais sobre remanescentes das superfícies de aplainamentos neogênicas, assim como vinculadas aos diferentes níveis de terraços fluviais na bacia do Ribeirão Araquá. Embora, essas coberturas tenham sido estudadas por Bjornberg (1965), Penteado (1968a) e Oliveira (1992), questões sobre processos erosivos-deposicionais e ambientes deposicionais permanecem pouco explorados, sobretudo no âmbito de datações absolutas por LOE. Destaca ainda, que a importância da área para esse estudo também está correlacionada ao fato de que seu desenvolvimento em um sistema horst-gráben (Oppenheim e Malamphy, 1936), possibilitou seu comportamento geomorfológico como uma expressiva (sub) bacia de sedimentação no interior da Depressão Periférica Paulista e, portanto, mantém registros de processos geomorfológicos complexos atuantes por um extenso intervalo de tempo geológico.

De modo geral, acredita-se que as coberturas superficiais presentes na área, apresentam correspondências com eventos climáticos registrados não apenas no estado de São Paulo, mas também com aqueles verificados em âmbito global. Assim, a hipótese de controles climáticos na espacialização das coberturas superficiais, tem como base os diversos trabalhos que apontam para a ocorrência de ciclos climáticos quaternários no estado de São Paulo (SalgadoLabouriau et al., 1998; Mayewski et al. 2004, ScheelYbert, 2000; Behling, 1995; 2002) e no globo (Wanner et al. 2011). Particularmente sobre os terraços fluviais, o trabalho desenvolvido por Perez Filho et al. (1980) apresentam importantes correlações com os resultados de Dias e Perez Filho (2015), Dias e Perez Filho (2016); Storani e Perez Filho (2015) e Souza e Perez Filho (2016b), inclusive com os trabalhos de Macklin et al. $(2010 ; 2013)$ sobre terraços fluviais no Reino Unido. Menciona-se ainda, correspondências entre as idades absolutas apresentadas nesses trabalhos com as proposições de Bond et al. $(1997 ; 2001)$ sobre curtos ciclos climáticos holocênicos.

\section{2. Área de estudo}

A bacia hidrográfica do Ribeirão Araquá está localizada no estado de São Paulo, drenando diferentes setores dos municípios de São Pedro e Charqueada (Figura 1). A bacia abrange aproximadamente 279,20 $\mathrm{Km}^{2}$, sendo que o Ribeirão Araquá tem aproximadamente 38 km de extensão, cuja orientação geral é de norte-sul. As nascentes principais estão localizadas na Serra de Itaqueri a norte e a dos afluentes da margem direita, na escarpa leste da Serra de São Pedro.

A área estudada abrange a Zona do Médio Tietê (Ab'Saber, 1955), a qual apresenta relevo diversificado resultante dos processos vinculados a província tectônica Paraná e a complexidade relacionada à transição entre duas unidades geomorfológicas do estado de São Paulo: a Depressão Periférica Paulista e Zona das Cuestas (Ab'Saber, 1955; 1969; Almeida, 1964; Penteado, 1968a; Almeida et al., 1981). 

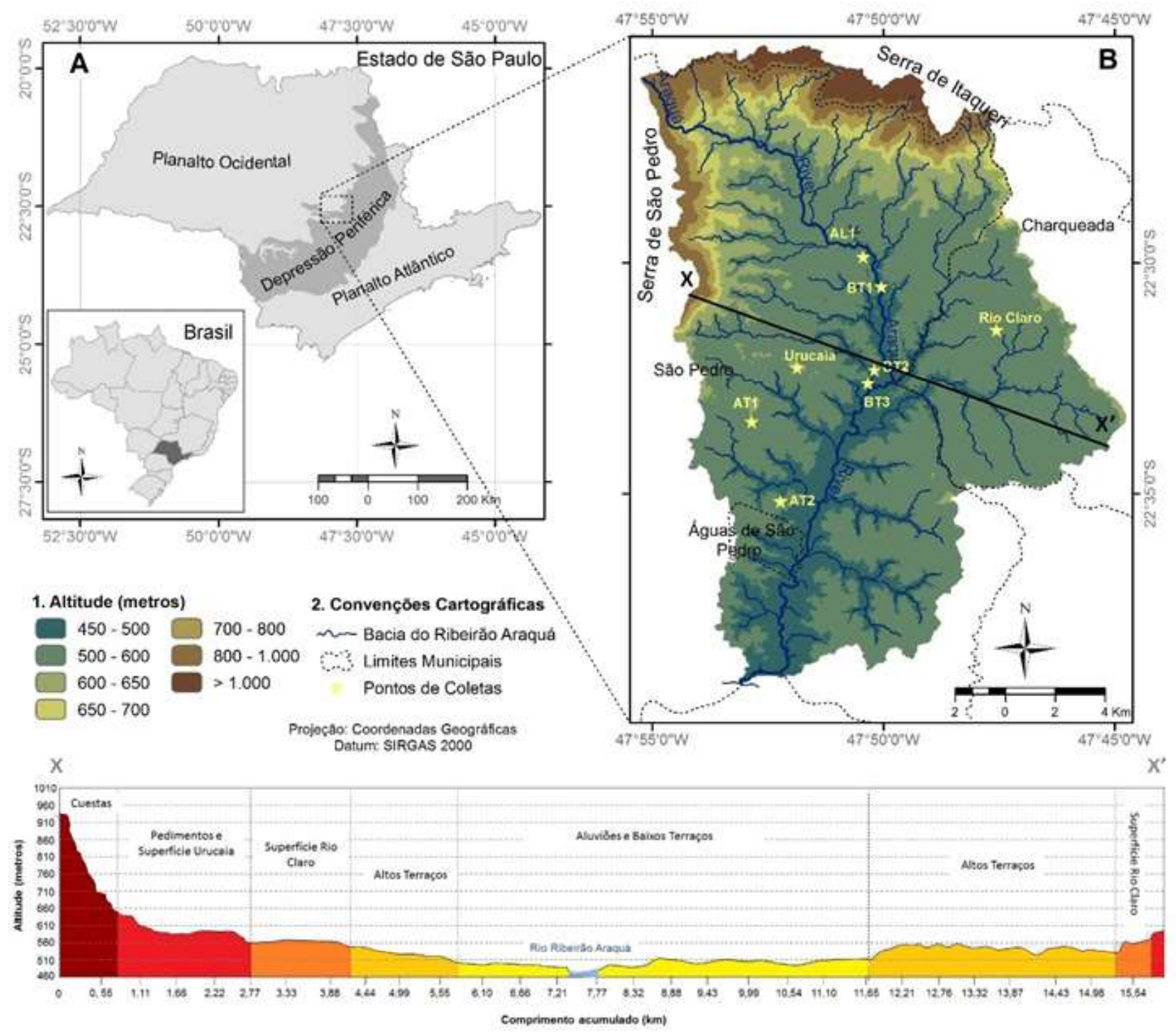

Figura 1 - A) Localização da área e compartimentos geomorfológicos do estado de São Paulo. B) Bacia hidrográfica do Ribeirão Araquá. AT1: Alto Terraço. AT2: Alto Terraço 2. BT1: Baixo Terraço 1. BT2: Baixo Terraço 2. BT3: Baixo Terraço 3. AL1: Aluvião. Urucaia: amostras coletadas sobre a Superficie Urucaia. Rio Claro: amostras coletadas sobre a Superfície Rio Claro. Fonte: IBGE (2010); Gdem Aster (2014).

As altitudes mais elevadas na área estão associadas aos topos da Serra de São Pedro e Serra de Itaqueri (cotas maiores do que 800 metros) (Souza e Perez Filho, 2016a), as quais são sustentadas principalmente por basaltos e dacitos da Formação Serra Geral (Peixoto e Theodorovicz, 2009). Segundo Almeida e Carneiro (2004), esses tipos litológicos estão vinculados aos eventos de magmatismo alcalino e localmente efusivo ocorridos em diversas regiões durante o Triássico e o Eocretáceo. No âmbito topográfico, Melo (1995) aponta que na bacia do Ribeirão Araquá e adjacências são identificados cinco níveis: o Nível Planáltico A (altitudes superiores a 800 metros); Nível Planáltico I (cotas entre
720 a 800 metros); Nível Planáltico B (cotas entre 610 a 750 metros), o qual corresponde à primeira superfície rebaixada e abrange toda a porção limítrofe entre as Cuestas e Depressão Periférica; e Nível Planáltico Bd (550 a 680), primeiro subnivelamento entre o topo das colinas da área da Depressão Periférica. Salienta-se que os níveis B e Bd compõem as Superfícies Neogênicas (Martonne, 1943; Ab'Saber, 1969). Finalmente, o Nível Planáltico R corresponde ao nivelamento dos topos baixos da cota de 590 metros e vinculados às calhas dos rios Piracicaba e Tietê.

$\mathrm{Na}$ área também são identificados pedimentos localizados a 550-650 metros de altitude, os quais 
se encontram parcialmente dissecados, sobretudo, aqueles localizados nas cotas de 550-570 metros de altitude (Barreto, 1970). Esse fato também foi evidenciado nas declividades que variam de 17 a $30 \%$ em alguns setores. Oliveira (1992) aponta que o conjunto de pedimentos (chamada pela autora de glacis) identificados na região de São Pedro pode ser dividido em três setores: o menos dissecado, a transição para o mais dissecado e o setor dissecado. Queiroz Neto e Journaux (1978) correlacionaram os "glacis" dessa região como elaborados por processos de pedimentação relacionada à primeira grande fase seca do Quaternário (Plio-Pleistoceno).

$\mathrm{Na}$ área da bacia, essas características geomorfológicas também são responsáveis por sustentar diferentes classes de solos, como Latossolos VermelhoAmarelo encontrado nos topos das serras; Argissolos Vermelho-Amarelo localizados na Depressão Periférica Paulista; Neossolos Quartazarênicos associados aos pedimentos da margem direita do Ribeirão Araquá (Souza e Perez Filho, 2016a); e por fim, Neossolos Litólicos presentes em vertentes com alto gradiente de declividade, as quais estão associadas às escarpas da Serra de Itaqueri e da Serra de São Pedro (IAC e IGC, 1989)

Sobrejacentes às litologias da Formação Serra Geral e, em alguns casos, também dos arenitos de origem eólica da Formação Botucatu, é possível encontrar a Formação Itaqueri. De acordo com Etchebehere et al. (2004), as litologias dessa formação compõem as coberturas sedimentares depositadas após os eventos magmáticos ocorridos na Bacia do Paraná, e estão associadas a extensa sedimentação cretácica e também aos eventos deposicionais mais restritos ocorridos durante o Cenozoico. A Fm Itaqueri é constituída pela alternância de fácies arenosas, conglomeráticas e argilosas relacionadas a fluxos aquosos de alta energia.

Segundo Melo (1995), sobre os níveis planálticos I, B, Bd são encontrados extensos depósitos arenoargilosos, delgados, sem estruturas sedimentares e de idade quaternária, os quais correspondem à Formação Santa Rita do Passa-Quatro. Souza e Perez Filho, (2016a) mencionam que essa formação também foi identificada por outros autores, mas com diferentes conceituações (Bjornberg, 1965; Bjornberg e Landim, 1966, Penteado, 1968a,b; Massoli, 1980).

Em relação aos aspectos estruturais, movimentos transcorrentes associados ao alinhamento São CarlosLeme (WNW) e também às zonas de cisalhamentos que controlam as dinâmicas estruturais de sistemas fluviais regionais, tais como o Rio Tietê (NW), o Rio Moji-Guaçu (NNW); são mencionados por Riccomini (1997). No mesmo sentido, Sousa (2002) sugere a influência de lineamentos orientados conforme E-W e N-S na bacia do rio Corumbataí, sistema adjacente à bacia do Ribeirão Araquá. Segundo Penteado (1968b) e Bjornberg $(1965 ; 1966)$, associados aos principais trends, importantes formas e feições alinhadas regionalmente para ENE-WSW, NNE-SSW, NW-SE, assim como falhamentos secundários de orientações SW-NE e NNW-SSE, influenciaram na sedimentação de coberturas quaternárias que, atualmente, recobrem alguns interflúvios na bacia do rio Corumbataí.

Analisando perfis lateríticos na Serra de Itaqueri, Dos Santos e Ladeira (2006) encontraram falhamentos de orientações NE-SW, NW-SE, E-W e N-S, os quais foram atribuídos a ocorrência de eventos neotectônicos durante o Cenozoico. Convergindo com essas afirmações, trabalhos desenvolvidos por Pinheiro e Queiroz Neto (2015) sugerem a ocorrência de condicionamentos dos canais de primeira e segunda ordem por lineamentos predominantemente orientados para NW-SE, N-S e WNW-ESSE, os quais estariam associados aos regimes de tensões sub-horizontais NW-SE e NE-SW.

Oppenheim e Malamphy (1936) apontam a ocorrência de um relevo topograficamente mais rebaixado na área abrangida pela bacia do Ribeirão Araquá. Na ocasião, os autores sugerem que a "Depressão de São Pedro" integraria um sistema do tipo horst-graben integrado com a alto esrtutural de Pitanga e, portanto, estaria relacionado a uma zona de cisalhamento regional com reduzida projeção vertical e dispostas "en echelon" de leste para oeste, compondo um conjunto de depressões na Depressão Periférica Paulista (Souza e Perez Filho, 2016a)

\section{Método e Metodologia}

A metodologia buscou a integração de informações sedimentológicas e datações por LOE com aspectos topográficos da bacia do Ribeirão Araquá. Ressalta-se que também foi realizada uma comparação entre os resultados publicados em periódicos com aqueles obtidos por meio das metodologias mencionadas, buscando correlacionar os aspectos locais com aqueles regionais. 


\subsection{Luminescência Opticamente Estimulada (LOE)}

Desde que datações de eventos ambientais por meio da Luminescência Opticamente Estimulada (LOE) foi proposta por Huntley et al. (1985), essa técnica tem sido amplamente utilizada em estudos geomorfológicos, principalmente aqueles que analisam depósitos de materiais inconsolidados quaternários. A eficiência da LOE na datação de eventos erosivos-deposicionais está relacionada à possibilidade de mensurar a idade (entre algumas centenas e 1 milhão de anos) em que determinada amostra foi exposta pela última vez à radiação solar, portanto, é uma técnica que avalia a quantidade de elétrons aprisionados na estrutura cristalina de alguns minerais, nesse caso feldspato e quartzo.

Nesta pesquisa, foram realizadas datações por LOE em 12 amostras de coberturas superficiais coletadas em diferentes pontos dentro da bacia do Ribeirão Araquá, as quais estão vinculados às superfícies neogênicas, planícies e terraços fluviais. Os materiais foram coletados com a inserção na horizontal de tubos de PVC (Polyvinyl Chloride) de coloração escura em profundidades que variaram de 40 a 110 centímetros. Após esse procedimento, as extremidades dos tubos foram fechadas e os mesmos envolvidos em plásticos de cor preta para inviabilizar a contaminação da amostra com radiação solar.

Em laboratório as amostras foram submetidas ao protocolo SAR (Single-Aliquot Regenerative-Dose), onde foi possível obter 15 curvas de calibração (15 alíquotas), como proposto por Murray \& Wintle (2000), permitindo assim, melhor acurácia na obtenção das idades absolutas. A equação para o cálculo da idade absoluta é apresentada abaixo:

$$
I=\frac{P}{D A \gamma+D A \beta+D A r \cdot c}
$$

onde: $\mathrm{I}=$ Idade; $\mathrm{P}=$ Paleodose $(\mathrm{G} \gamma)$, que corresponde à energia total absorvida pelo cristal pela incidência de radiações ionizantes; DA $\gamma+\mathrm{DA} \beta+\mathrm{DAr} . \mathrm{c}=$ doses anuais (G $\gamma /$ ano) relativas às radiações- $\gamma$, partículas- $\beta$ e aos raios cósmicos respectivamente (Murray \& Wintle, 2000).

Por fim, é importante destacar que os procedimentos foram desenvolvidos pelo Laboratório Datação, Comércio e Prestação de Serviços LTDA, sob a supervisão do Dr. Silvio Luiz Miranda Brito.

\subsection{Granulometria}

A análise granulométrica foi realizada no Laboratório de Pedologia - Labsol - da Faculdade de Engenharia Agrícola (FEAGRI) da Universidade Estadual de Campinas (Unicamp) e contemplou a separação das amostras em frações de areia muito grossa $(1.0 \mathrm{~mm})$, grossa $(0,50 \mathrm{~mm})$, média $(0,25 \mathrm{~mm})$, fina $(0,125 \mathrm{~mm})$ e muito fina $(0,053 \mathrm{~mm})$, além das frações de argila e silte pelo método da pipeta (Camargo et al. 1986). Em campo, os materiais foram coletados em profundidades que variaram de $0-20$ a 200 centímetros, onde se verificaram descontinuidades deposicionais e discreta remobilização por atividade antrópica. Os resultados obtidos foram enquadrados em classes texturais de acordo com o manual da USDA (1993).

\subsection{Morfoscopia}

As análises dos parâmetros geométricos de grãos de quartzo possibilitam avaliar características ambientais responsáveis pelo transporte, o tempo em que o material permaneceu no ciclo sedimentar, fábrica deposicional, intensidade do intemperismo químico, controles litológicos e classificar os grãos quanto à sua forma (Suguio, 1993; Tucker, 1995).

No presente trabalho, por meio de lupa eletrônica, foram analisados grãos de quartzo da fração areia das coberturas superficiais sobrepostas as Superfícies Urucaia e Rio Claro, cuja finalidade foi verificar características do ambiente de transporte e deposição. Destaca-se que foi utilizada a metodologia propostas por Bullock et al. (1985), a qual classifica as morfologias dos grãos conforme a esfericidade, rugosidade e grau de arredondamento.

\section{Resultados}

\subsection{Aplainamentos Neogênicos}

Os resultados das coberturas analisadas na bacia do Ribeirão Araquá, indicaram que os materiais que recobrem os Aplainamentos Neogênicos tiveram sua gênese relacionada a eventos com características ambientais distintas (Quadro 1). Também foi verificado que essas coberturas se encontram em posições topográficas mais rebaixadas em relação àquela identificada por Penteado (1968a) e Dias e Perez Filho (2014) em áreas adjacentes. Os perfis onde foram 
coletadas as amostras são representados pela Figura 2 e estão associados a dois pontos representativos em relação às dimensões espaciais da bacia do Ribeirão Aráquá. Além disso, as limitações nas disponibilidades dos recursos também contribuíram para um número restrito de amostras coletadas, tanto para datações absolutas por LOE quanto para as demais análises físico-químicas.

Quadro 1: Datações por LOE e granulometrias das coberturas presentes nas Superfícies Neogênicas

\begin{tabular}{|c|c|c|c|c|c|c|c|}
\hline \multirow{2}{*}{ Ponto } & \multirow{2}{*}{$\begin{array}{c}\text { Altitude } \\
\text { do ponto } \\
\text { (metros) }\end{array}$} & $\begin{array}{c}\text { Profundidade } \\
\text { de coleta no } \\
\text { perfil (cm) }\end{array}$ & \multirow{2}{*}{ Idade (AP) } & \multicolumn{2}{|c|}{$\begin{array}{c}\text { Granulometria } \\
\text { (\%) }\end{array}$} & \multirow{2}{*}{ Textura } \\
\cline { 3 - 7 } & \multirow{2}{*}{600} & $0-20$ & & & & & \\
\cline { 5 - 8 } & & 50 & $12.300 \pm 2.370$ & 86,9 & 10,0 & 3,1 & Areia-Franca \\
\hline \multirow{2}{*}{ RIO CLAROAIA } & \multirow{2}{*}{570} & $0-20$ & & 82,0 & 9,0 & 9,0 & $\begin{array}{c}\text { Franco- } \\
\text { Arenosa }\end{array}$ \\
\cline { 5 - 7 } & & 50 & $8.100 \pm 820$ & 77,0 & 14,6 & 8,4 & $\begin{array}{c}\text { Franco- } \\
\text { Arenosa }\end{array}$ \\
\hline
\end{tabular}

Legenda: A cota altimétrica foi aferida com o auxílio do GPS que apresenta erro padrão de 3 metros de altitude. Organização: Autores, 2016

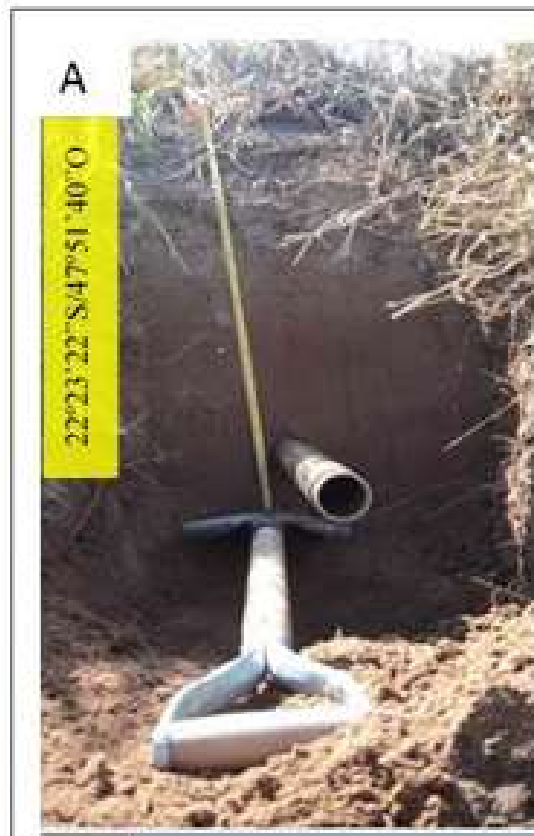

B

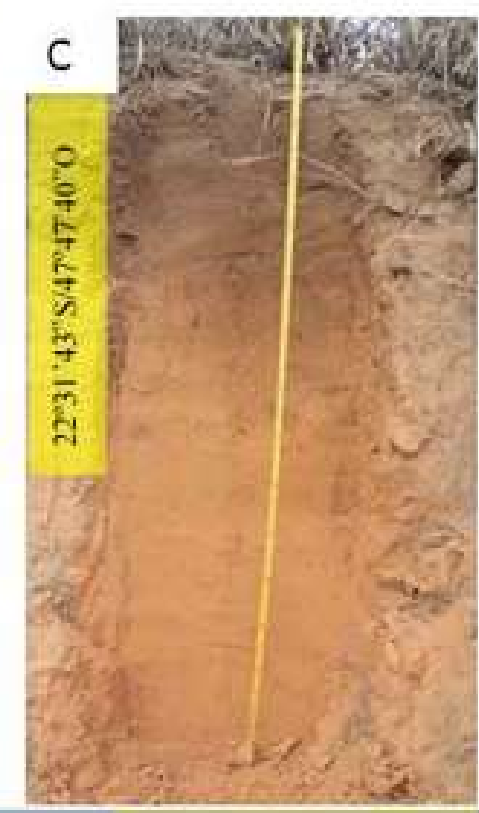

$22^{\circ} 2322^{\prime \prime} \mathrm{S} / 47 \div 51^{\prime} 40^{\circ} \mathrm{O}$

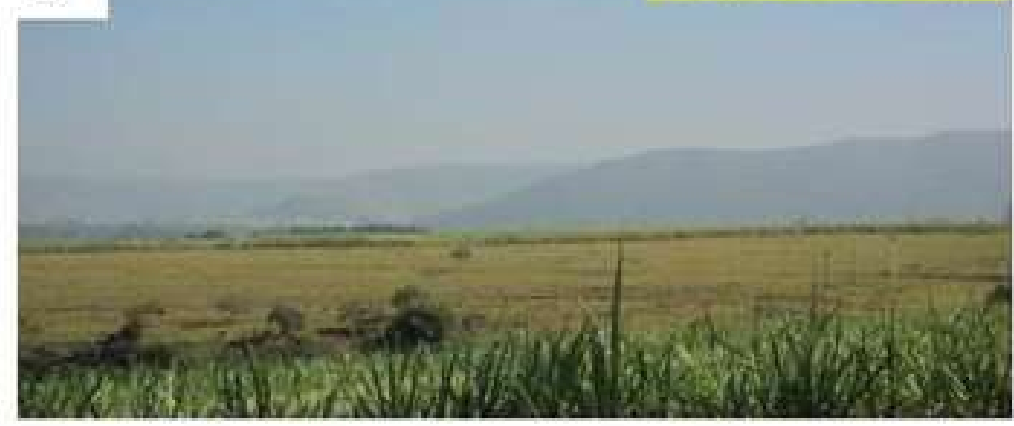

Figura 2 - Perfis onde foram coletadas as amostras de coberturas relacionadas aos possíveis aplainamentos neogênicos. A) Perfil de coleta da cobertura do Aplainamento Urucaia. B) Visão panorâmica do ponto onde foi coletada a amostra referente ao Aplainamento Urucaia. C) Perfil de coleta do Aplainamento Rio Claro. Fonte: Autores, 2014. 
Os dados apresentados no quadro acima destacam as características diferenciadas das amostras coletadas. Nas amostras coletadas predominam a fração de areia em detrimento das frações de argila e silte, embora existam algumas diferenças da porcentagem dessas frações entre as amostras URUCAIA, coletadas a 600 metros de altitude; e a RIO CLARO, coletada a 570 metros. Em relação às idades obtidas, na superfície mais elevada (URUCAIA) a idade de $12.300 \pm 2.370$ AP indica alguma mudança ambiental responsável pela deposição do material de textura Areia-Franca; enquanto que na superfície imediatamente abaixo (RIO CLARO) as coberturas superficiais apresentaram idades $8.100 \pm 820$ AP e textura Franco-Arenosa, decorrente da maior concentração de argila e silte nas amostras. Em ambos os casos, as idades apresentam correspondências com importante eventos climáticos ocorridos em escala global: o Último Máximo Glacial (transição Pleistoceno/Holoceno) e à transição entre primeira fase de deglaciação e o Optimum Climático holocênico (Holoceno Médio) (Thomas e Thorp, 1995; Behling, 2002; Wanner et al., 2011).

Análises morfoscópicas de 200 grãos de quartzos da fração areia total das amostras URUCAIA e RIO CLARO (100 grãos cada amostra), revelaram diferenças no arredondamento e esfericidade entre cada conjunto de grãos; sugerindo a ocorrência de diferentes condições de transporte (Tucker, 1995) (Figura 3). Deste modo, no conjunto de grãos da cobertura superficial da superfície mais elevada predominam grãos subesféricos a subalongados, com grau de arredondamento predominantemente subangular a angular e pouco brilho. Por outro lado, os grãos da amostra coletadas sobre a superfície mais rebaixada apresentam formatos variando de subesférico a esférico, com grau de arredondamento tendendo ao arredondado e foscos.

Embora, a textura dos grãos não seja suficiente para afirmar as condições ambientais durante o transporte e deposição; a correspondência entre as idades absolutas e características geométricas dos grãos com os ambientes mencionados por Behling (2002) e Wanner et al. (2011), permitem sugerir que os processos erosivos-deposicionais, relacionados às coberturas superficiais das amostras URUCAIA $\mathrm{e}$ RIO CLARO, responderam a condições ambientais distintas. Assim, é provável que a $12.300 \pm 2.370$ tenha predominado processos geomorfológicos vinculados a ambientes com menor umidade, enquanto que a $8.100 \pm 820$ predominaram ambientes mais úmidos, correspondendo, respectivamente, aos ambientes estabelecidos durante a transição Pleistoceno/Holoceno (semiúmido) e Holoceno Médio (úmido-quente).
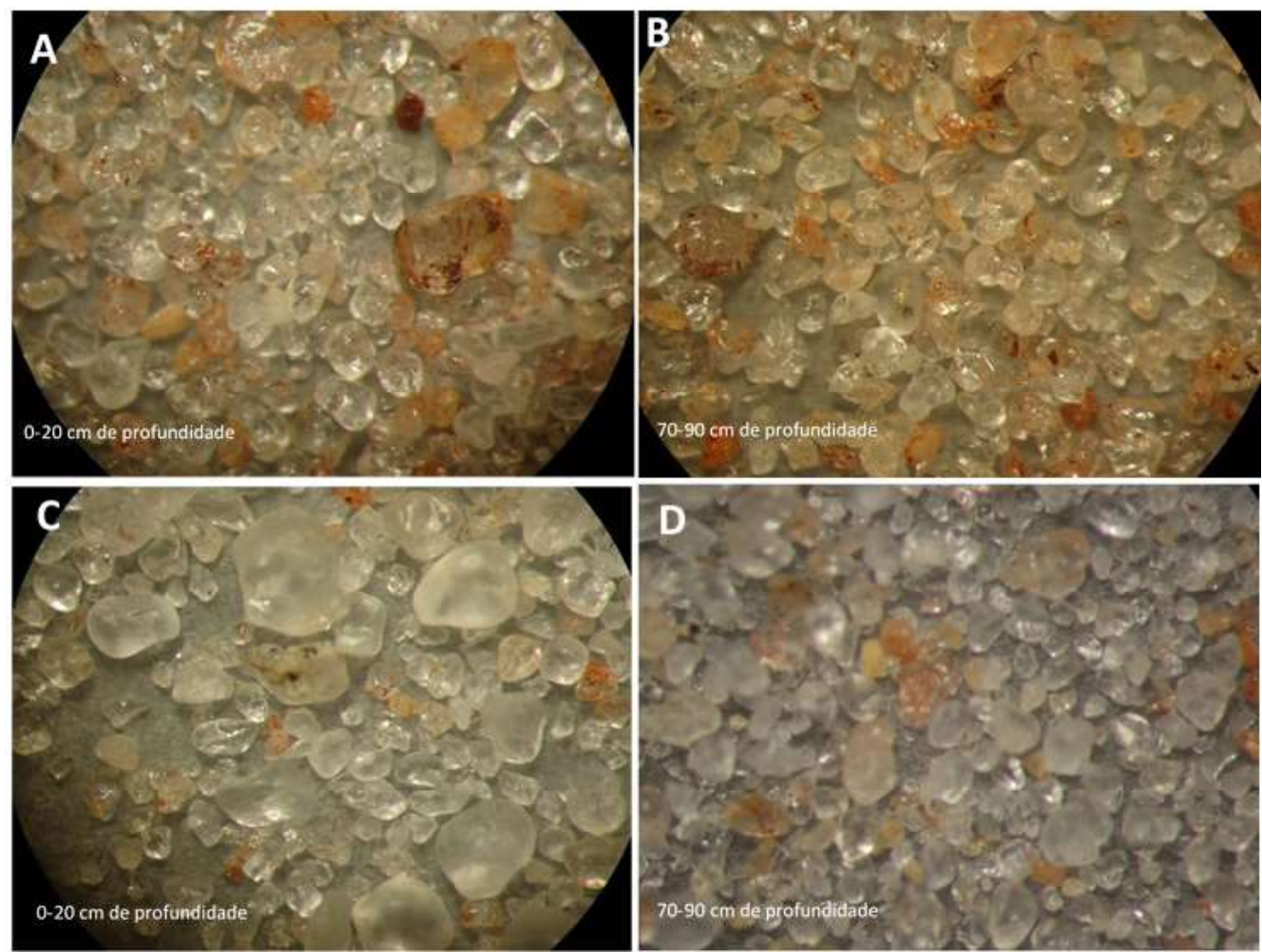

Figura 3 - Imagens dos grãos usados para a análise morfoscópica. A - B: Grãos correspondentes a amostra URUCAIA. C-D: Grãos correspondentes a amostra RIO CLARO. Fonte: Autores, 2016. 


\subsection{Terraços Fluviais}

Foram encontrados diferentes níveis de terraços fluviais na bacia do Ribeirão Araquá, sendo 2 altos terraços ( $>30$ metros acima da superfície da água) e 3 níveis de baixos terraços $(<10$ metros acima da superfície da água) (Figura 4). Os altos terraços apresentam linhas de cascalhos embutidos, as quais são compostas por seixos de diferentes tamanhos e mineralogias (basaltos, arenitos e quartzitos). Os baixos terraços apresentaram materiais sedimentares pouco coeso e raras estruturas sedimentares; excetuando aquele onde prevalecem maiores porcentagens da fração de argila e silte (BT3). Os resultados obtidos para os diferentes níveis de terraços são apresentados no Quadro 2 e os perfis onde foram coletadas as amostras na Figura 5.

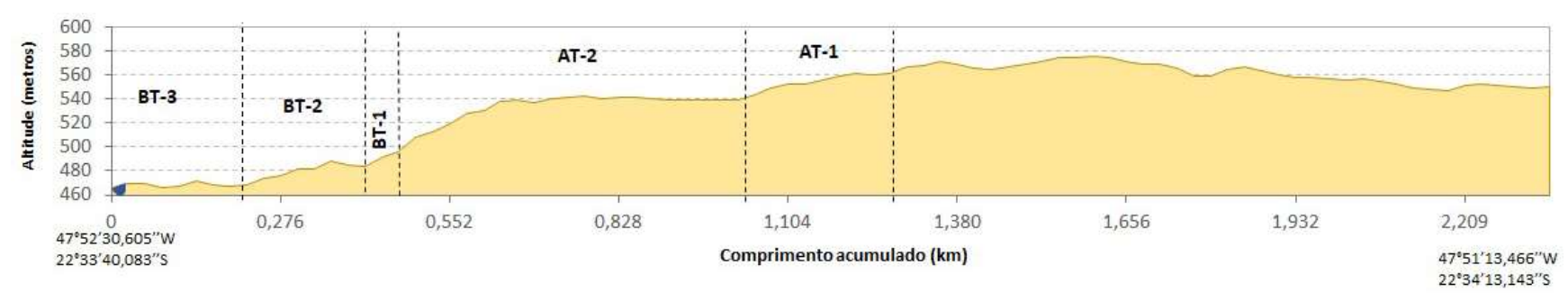

Figura 4 - Perfil topográfico elaborado a partir do raster Gdem Aster (2014). AT-1) Alto Terraço 1; AT-2) Alto Terraço 2; BT-1) Baixo Terraço 1; BT-2) Baixo Terraço 2 e; BT-3) Baixo Terraço 3 Elaboração: Autores, 2017.

Quadro 2: Dados de coleta referentes aos terraços e aluviões do Ribeirão Araquá

\begin{tabular}{|c|c|c|c|c|c|c|c|c|}
\hline \multirow[b]{2}{*}{ Abreviação } & \multirow{2}{*}{$\begin{array}{c}\text { Altitude } \\
\text { em } \\
\text { relação } \\
\text { ao nível } \\
\text { do mar } \\
(\mathrm{m}) \\
\end{array}$} & \multirow{2}{*}{$\begin{array}{l}\text { Altitude } \\
\text { da } \\
\text { superfície } \\
\text { da água }\end{array}$} & \multirow{2}{*}{$\begin{array}{c}\text { Profundidade } \\
\text { de coleta no } \\
\text { perfil }(\mathrm{cm})\end{array}$} & \multirow[b]{2}{*}{$\begin{array}{l}\text { Idade } \\
\text { (A.P) }\end{array}$} & \multicolumn{3}{|c|}{ Granulometria (\%) } & \multirow[b]{2}{*}{ Textura } \\
\hline & & & & & Areia & Argila & Silte & \\
\hline \multirow{2}{*}{$\begin{array}{c}\text { Alto Terraço } \\
1 \text { (AT1) }\end{array}$} & \multirow{2}{*}{560} & \multirow{2}{*}{500} & 480 & $\begin{array}{c}59.550 \pm \\
9.260 \\
\end{array}$ & 81,4 & 13,5 & 5,1 & $\begin{array}{l}\text { Franco- } \\
\text { Arenosa }\end{array}$ \\
\hline & & & 500 & $\begin{array}{c}60.000 \pm \\
7.715\end{array}$ & 82,8 & 12,9 & 4,3 & $\begin{array}{l}\text { Franco- } \\
\text { Arenosa }\end{array}$ \\
\hline \multirow{2}{*}{$\begin{array}{l}\text { Alto Terraço } \\
2 \text { (AT2) }\end{array}$} & \multirow{2}{*}{530} & \multirow{2}{*}{500} & 180 & $\begin{array}{c}13.900 \pm \\
940\end{array}$ & 75,5 & 18,6 & 5,9 & $\begin{array}{l}\text { Franco- } \\
\text { Arenosa }\end{array}$ \\
\hline & & & 220 & $\begin{array}{c}35.000 \pm \\
2.860\end{array}$ & 77,5 & 16,9 & 5,6 & $\begin{array}{l}\text { Franco- } \\
\text { Arenosa }\end{array}$ \\
\hline $\begin{array}{l}\text { Baixo } \\
\text { Terraço } \\
\text { (BT1) } \\
\end{array}$ & $\begin{array}{c}493 \\
\text { metros }\end{array}$ & 488 metros & 60 & $\begin{array}{c}9.850 \pm \\
1.120\end{array}$ & 98,4 & 0,8 & 0,8 & Arenoso \\
\hline $\begin{array}{l}\text { Baixo } \\
\text { Terraço } \\
\text { (BT2) } \\
\end{array}$ & $\begin{array}{c}482 \\
\text { metros }\end{array}$ & 479 metros & 70 & $\begin{array}{c}2.780 \pm \\
410\end{array}$ & 98,2 & 1,1 & 0,7 & Arenoso \\
\hline $\begin{array}{l}\text { Baixo } \\
\text { Terraço } \\
\text { (BT3) } \\
\end{array}$ & $\begin{array}{c}481 \\
\text { metros }\end{array}$ & 479 metros & 80 & $\begin{array}{c}1.481 \pm \\
215\end{array}$ & 26,3 & 37,8 & 35,9 & $\begin{array}{l}\text { Franco- } \\
\text { Argilosa }\end{array}$ \\
\hline \multirow{2}{*}{$\begin{array}{l}\text { Aluvião } \\
\text { (AL) }\end{array}$} & \multirow{2}{*}{$\begin{array}{c}493 \\
\text { metros }\end{array}$} & \multirow{2}{*}{492 metros } & 70 & $300 \pm 50$ & 89,3 & 3,9 & 6,8 & Arenoso \\
\hline & & & 110 & $610 \pm 135$ & 86,1 & 6,0 & 7,9 & Areia-Franca \\
\hline
\end{tabular}

Legenda: As cotas altimétricas foram aferidas com o auxílio do GPS que apresenta erro padrão de 3 metros de altitude. Fonte: Adaptado de Souza e Perez Filho (2015) 
O primeiro nível de Alto Terraço (AT1), localizado a 60 metros acima da superfície da água, apresenta um pacote sedimentar com espessura superior aos 5 metros, sendo que a $490 \mathrm{~cm}$ de profundidade foi encontrada uma linha de cascalhos de aproximadamente $20 \mathrm{~cm}$ de espessura (Figura 5A). Como demonstrado no Quadro 2, foram coletadas amostras em duas profundidades diferentes para a realização de análises granulométricas. As coberturas coletadas a 480 centímetros de profundidade apontaram a predominância da fração areia $(81,4 \%)$, enquanto

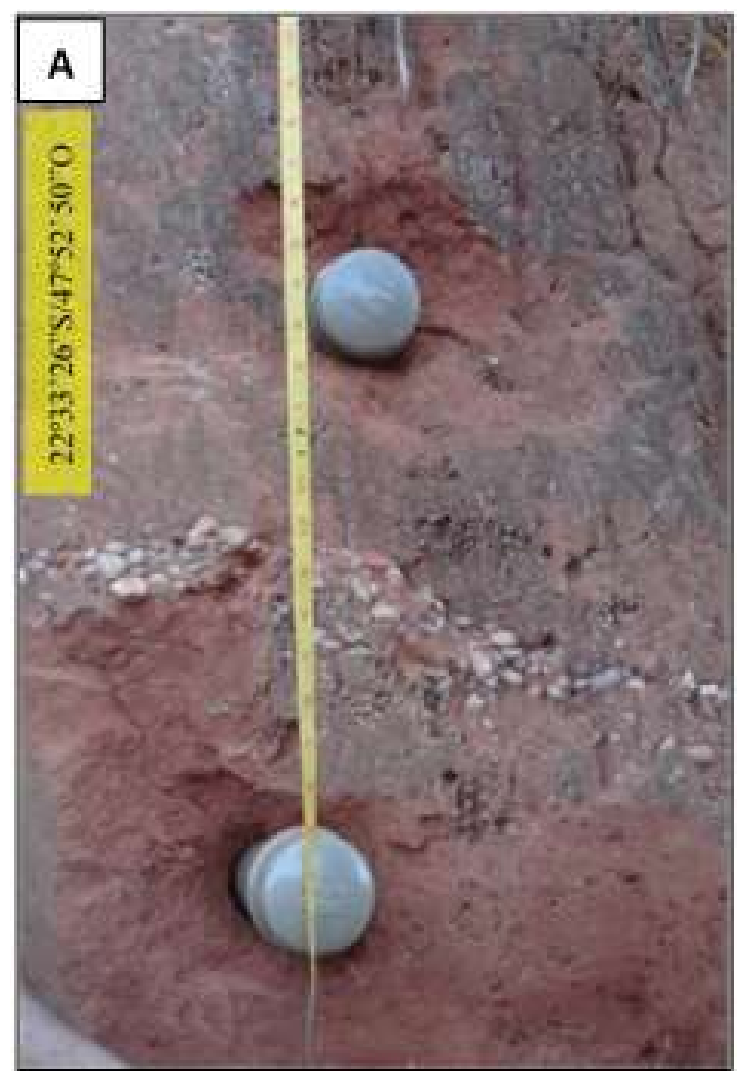

que as frações de argila e silte compreendem, respectivamente, $13,5 \%$ e $5,1 \%$. Similarmente, a 500 centímetros de profundidade também predominam a fração areia (82,8\%), enquanto que as frações de argila e silte compreendem respectivamente $12,9 \%$ e $4,3 \%$. Interessante observar que as composições granulométricas de amostras coletadas acima e abaixo da linha de cascalho não apresentaram variações significativas, sugerindo a ocorrência de processos erosivos-deposicionais similares com um intervalo de tempo aproximadamente de 1000 anos.

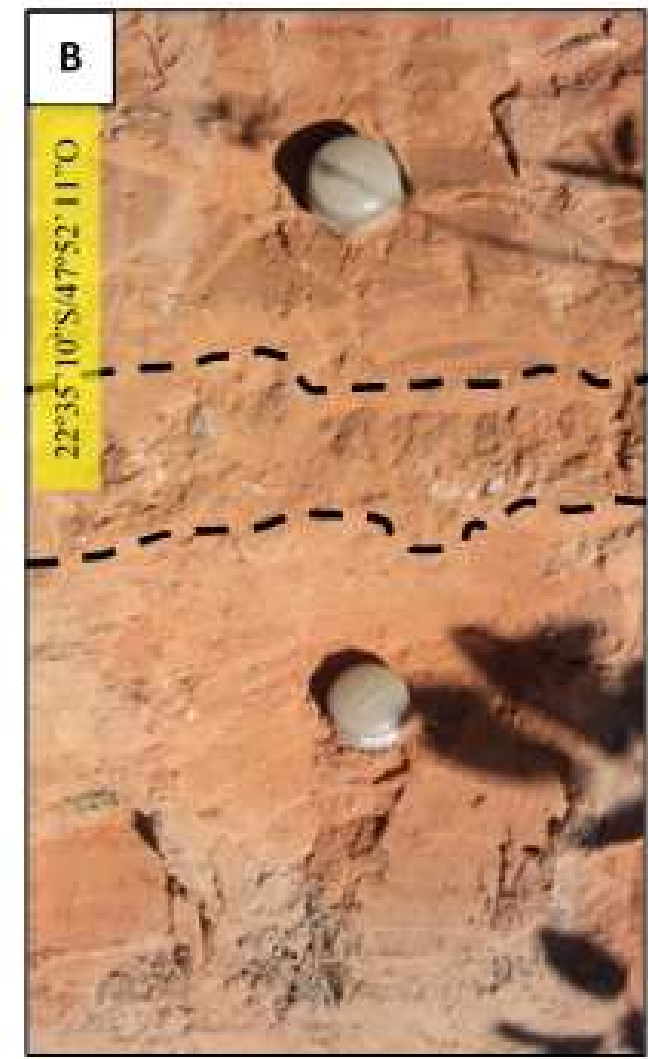

Figura 5 - Nas figuras acima estão demonstrados os perfis onde foram coletadas as amostras das coberturas superficiais dos altos terraços. A) Alto Terraço 1 (AT1). B) Alto Terraço 2 (AT2). A linha tracejada delimita a linha de cascalho pouco evidente no AT2. Fonte: Souza e Perez Filho (2016a).

No segundo nível de Alto Terraço (AT2), o pacote sedimentar onde foram coletadas amostras de coberturas superficiais tem aproximadamente 220 centímetros de espessura e, assim como no nível AT1, é possível identificar uma linha de cascalhos (Figura 5B). Nesse nível, a linha de cascalho apresenta uma espessura um pouco maior em relação a encontrada no alto terraço anterior e está localizada a aproximadamente 190 centímetros de profundidade. As análises granulométricas dos materiais coletados acima e abaixo do cascalho apresentaram pouca variação, sendo 75,5\% de areia, $18,6 \%$ de argila e 5,9\% de silte acima da linha de cascalho; e $77,5 \%$ de areia, $16,9 \%$ de argila e 5,6\% de silte abaixo do cascalho.

Assim sendo, em ambos os níveis de alto terraços, as linhas de cascalhos verificadas são pouco espessas ( $\sim 10$ centímetros no nível AT 1 e $\sim 20$ centímetros no nível AT2), sugerindo que o aumento energético da hidrodinâmica fluvial, decorreu de intensos e rápidos ajustes no nível de base e, de acordo com Souza e Perez 
Filho (2016a), estão associados a processos de origem estrutural (nível AT1) e a ação concomitante de processos climáticos e estruturais (nível AT2). As datações das amostras coletadas acima e abaixo da linha das cascalheiras do primeiro nível de terraço apresentaram idades de $59.550 \pm 9.260$ AP para o material acima da cascalheira e $60.000 \pm 7.715 \mathrm{AP}$ para aqueles localizados logo abaixo da cascalheira (Figura 4A), indicando um curto intervalo de tempo entre a deposição dos dois materiais (Souza e Perez Filho, 2016a). No âmbito do nível AT2, localizado a 30 metros acima da superfície da água, as datações por Luminescência Opticamente Estimulada apontaram para as idades de $13.900 \pm 940$ a $180 \mathrm{~cm}$ de profundidade e $35.000 \pm 2.860$ a $220 \mathrm{~cm}$ de profundidade, respectivamente acima e abaixo de

uma linha de cascalho, porém ao contrário do AT1 o intervalo de tempo é maior (Figura 5B).

Os baixos terraços apresentam camadas com diferentes características na composição granulométrica e também geocronológica, as quais se relacionam a eventos erosivos-deposicionais distintos (Vandenberghe, 2015). Os diferentes níveis de baixos terraços compõem a planície fluvial do Ribeirão Araquá e estão localizados em média a 5-6 metros acima da superfície da água, característica que contribui para que os mesmos sejam recorrentemente inundados. Na Figura 6 é possível verificar que, em sua grande maioria, os terraços analisados apresentam sedimentos com pouca coesão como resultado da baixa porcentagem das frações granulométricas finas (silte e argila).
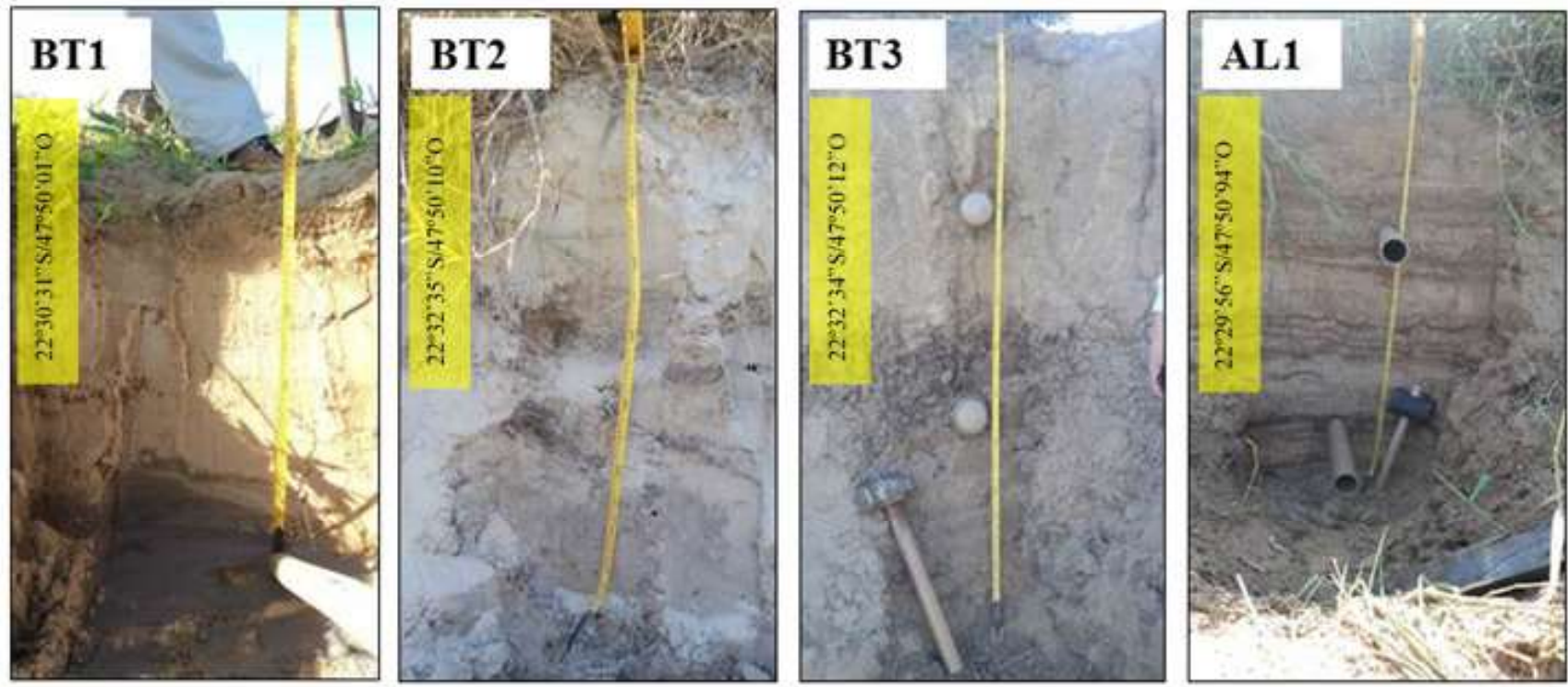

Figura 6 - Perfis onde foram coletadas as amostras das coberturas nos baixos terraços e aluviões. As coordenadas no quadro amarelo indicam o ponto de coleta. Fonte: Autores, 2014

De modo geral, as idades absolutas das coberturas superficiais obtidas pela LOE apontam para uma correspondência com eventos de alternâncias entre ambientes úmido-quente e mais secos-frio, os quais também foram verificados em outras partes do estado de São Paulo e em escala global (Thomas e Thorp, 1995; Schell-Ybert et al. 2003), assim como apresentam coalescências com os Ciclos de Bond (Bond et al., 1997; 2001), Pequena Idade do Gelo e Período de Aquecimento Medieval (Wanner et al., 2011).

Neste âmbito, no primeiro nível de baixo terraço, localizado $\sim 5$ metros acima da superfície da água (BT1), a datação por LOE demonstrou que a deposição dos sedimentos ocorreu por volta dos $9.850 \pm 1.120$
AP. A predominância de frações arenosas nas análises granulométricas indicam que o transporte fluvial dos sedimentos que formam, atualmente, as coberturas superficiais presentes nesse nível de terraço, foram provavelmente mais energéticas em decorrência da instabilidade ambiental relacionada ao término do UMG, ou seja, cronologicamente instabilidades ocorridas entre as deposições correspondentes as amostras P1-UC e P1-RC.

O nível BT2, localizado a $\sim 3$ metros acima da superfície da água, apresenta coberturas superficiais com a idade de $2.780 \pm 410$ AP e predominância da fração areia $(98,2 \%)$. No entanto, comparando com o nível BT1 é possível notar um aumento da fração argila 
$(1,1 \%)$ que indicaria a possibilidade de um ambiente, o qual proporcionasse menor energia hidrodinâmica do que os processos vinculados ao nível BT1. Assim, apesar da classificação granulométrica indicar a mesma classe, é importante destacar que as diferenciações sutis entre os componentes granulométricos de uma amostra, podem ser indicativos de processos erosivosdeposicionais diferentes.

O terceiro nível de baixo terraço (BT3) está localizado a $\sim 2$ metros acima da superfície da água, apresenta coberturas superficiais com idade de 1.481 \pm 215 AP e predominância das frações finas $(37,8 \%$ de argila e $35,9 \%$ de silte), enquanto que a fração areia representa $26,3 \%$ da amostra coletada. Os resultados sugerem que no final da Pequena Idade do Gelo e início do Período de Aquecimento Medieval (Wanner et al. 2011), mudança nas características de temperatura e umidade podem ter conduzido à diminuição energética da hidrodinâmica fluvial. Do mesmo modo, os resultados também encontram correspondência com os estudos desenvolvidos por Storani e Perez Filho (2012; 2015) e Valézio e Perez Filho (2015), os quais identificaram associações entre os níveis de baixos terraços em diferentes bacias da Depressão Periférica Paulista, com eventos climáticos holocênicos dos últimos 2.000 AP.

\section{Discussões}

Mudanças ambientais iniciadas no Pleistoceno Superior, tem sido demonstrada em diversos trabalhos desenvolvidos em partes do estado de São Paulo e em outras regiões do Brasil e do globo. Nesses trabalhos, os resultados têm apontado para fases climáticas mais secas do que o atual durante a transição PleistocenoHoloceno, o que favoreceu o estabelecimento do Cerrado de campo aberto e, posteriormente no Holoceno Inferior e Médio, ocorre um aumento da umidade e favorecendo a expansão de espécies $C_{3}$ (Behling, 2002; Gouveia et al. 2002; Scheel-Ybert et al. 2003; Wanner et al. 2011; Souza et al. 2013; Flantua et al. 2016).

\subsection{Dinâmica geomorfológica das coberturas superficiais durante o Pleistoceno Superior e Holoceno Médio.}

Trabalhos desenvolvidos na Depressão Periférica Paulista, apontam para a existência de aplainamentos neogênicos a partir dos 600 metros de altitude (Ab'Saber, 1969; Penteado, 1968a; Dias e Perez Filho, 2014). Nestes trabalhos, a superfície mais elevada e mais antiga estaria vinculada à Superfície Urucaia, identificada em cotas altimétricas variando entre 700-750 metros; enquanto que o aplainamento mais recente estaria associado a Superfície Rio Claro, em cotas altimétricas que variam de 600 a 670 metros. Em ambas, o recobrimento sedimentar teria origem nos processos morfoesculturais, vinculados aos eventos climáticos Quaternários correspondentes a transição Pleistoceno-Holoceno e, consequentemente, se diferenciam em diversos aspectos.

Nesse sentido, são reconhecidos na bacia do rio Corumbataí, área adjacente a bacia do Ribeirão Araquá, coberturas superficiais com distintas características morfológicas sobre ambos os aplainamentos, os quais sugerem a ocorrência de diferentes ambientes de sedimentação (Penteado, 1968). De acordo com Penteado (1968), as características do recobrimento da Superfície Urucaia indicariam ambientes semiúmidos e, portanto, o transporte deve ter ocorrido por meio de processos flúvioeólicos. Por outro lado, o material sobre a Superfície Rio Claro teria sido transportado principalmente por processos fluviais, sugerindo acréscimo da umidade.

Os resultados das análises morfoscópicas das coberturas superficiais coletadas a 600 metros de altitude na bacia do Ribeirão Araquá (amostra URUCAIA), apresentam importante correlações com os resultados obtidos por Penteado (1968) e Dias e Perez Filho (2014), uma vez que o brilho verificado nos grãos de quartzo sugere transporte aquoso, enquanto a angularidade e a subesfericidade, transporte eólico. Deste modo, as condições ambientais a $12.300 \pm 2.370$ (idade obtida por meio da datação absoluta por LOE) devem ter sido caracterizadas por um sutil aumento da umidade, vinculada ao término do Último Máximo Glacial (Thomas e Thorp, 1995; Thomas, 2008; Behling, 2002; Ortiz-Jaureguizar e Cladera, 2006). De acordo com esses autores, durante a transição Pleistoceno/ Holoceno as condições ambientais foram mais úmidas e de maior temperatura quando comparado ao período glacial pleistocênico, porém menos úmido do que o período atual. Behling (2002) analisando grãos de pólen das regiões sul e sudeste brasileira, verificou que nesse período a vegetação subtropical de campos foi substituída pelo cerrado tropical, provavelmente relacionada ao aumento da temperatura e também da umidade.

A amostra coletada a 570 metros de altitude, apresenta grãos com características que sugerem retrabalhamentos em ambientes mais úmido e quente do que durante a transição Pleistoceno/Holoceno e, portanto, diferente daquele associado à amostra URUCAIA. Os 
aspectos arredondados e subesféricos da amostra RIO CLARO indicariam essa possibilidade, mesmo que os grãos também apresentem pouco brilho, o que sugeriria transporte eólico. Assim, o fato dos grãos de quartzo apresentarem superfície menos polida e com menor brilho do que os grãos da amostra URUCAIA, poderia ser explicado por processo de corrosão química (PYE e TSOAR, 1990) e não necessariamente em decorrência de transporte eólico. Corroborando com essa hipótese, Wanner et al. (2011) aponta que de $8.300 \mathrm{AP}$ a $8.100 \mathrm{AP}$ no sudeste brasileiro é registrada uma "anomalia positiva" de umidade e temperatura; características ambientais também mencionadas por Stevaux (2000), Behling (2002) e Ortiz-Jaureguizar e Cladera (2006).

De modo geral, os resultados demonstram que as coberturas superficiais foram transportadas e depositadas por processos morfoesculturais relacionados a ambientes transicionais semiúmidos $(12.300 \pm 2.370 \mathrm{AP})$, assim como durante a fase de degelo e de maior umidade ocorrida entre 10.000 AP e 7.000 AP (Wanner et al. 2011). Deste modo, as amostras estariam associadas ao aumento progressivo da umidade desde o término do UMG, o qual permitiu o estabelecimento de ambientes com características diferentes, principalmente em relação a umidade. Assim, essas coberturas superficiais teriam gênese alóctone, sendo que no caso das coberturas vinculadas a amostra
URUCAIA, as áreas fontes seriam as Formações Itaqueri e Botucatu, as quais se encontram em posição topográfica superior à Superfície Urucaia. Por outro lado, as coberturas associadas à amostra RIO CLARO possivelmente não apenas apresentem correlações com os grupos litológicos supracitados, mas também com o retrabalhamento das coberturas superficiais URUCAIA.

No entanto, apesar de reconhecido os possíveis ambientes deposicionais dessas coberturas superficiais, alguns aspectos parecem poucos esclarecidos. Como é possível que materiais sedimentares com características tão similares daquelas encontradas regionalmente, estejam localizadas em cotas altimétricas tão distintas? A resposta parece estar associada à dinâmica do Gráben de São Pedro, o qual propicia um desnível de aproximadamente 60 metros na topografia regional (Oppenheim e Mallamphy, 1936; Facincani, 2000). Facincani (2000) e Souza e Perez Filho (2016a) sugeriram que eventos neotectônicos ocorridos no Pleistoceno Superior reativaram os principais trends, orientados principalmente para N-S, E-W, NW-SE e NE-SW, conduzindo à subsidência de blocos, deslocamento lateral do curso, elaboração de altos terraços e, concomitantemente, ao estabelecimento de níveis altimétricos distintos do entorno (Figura 7).

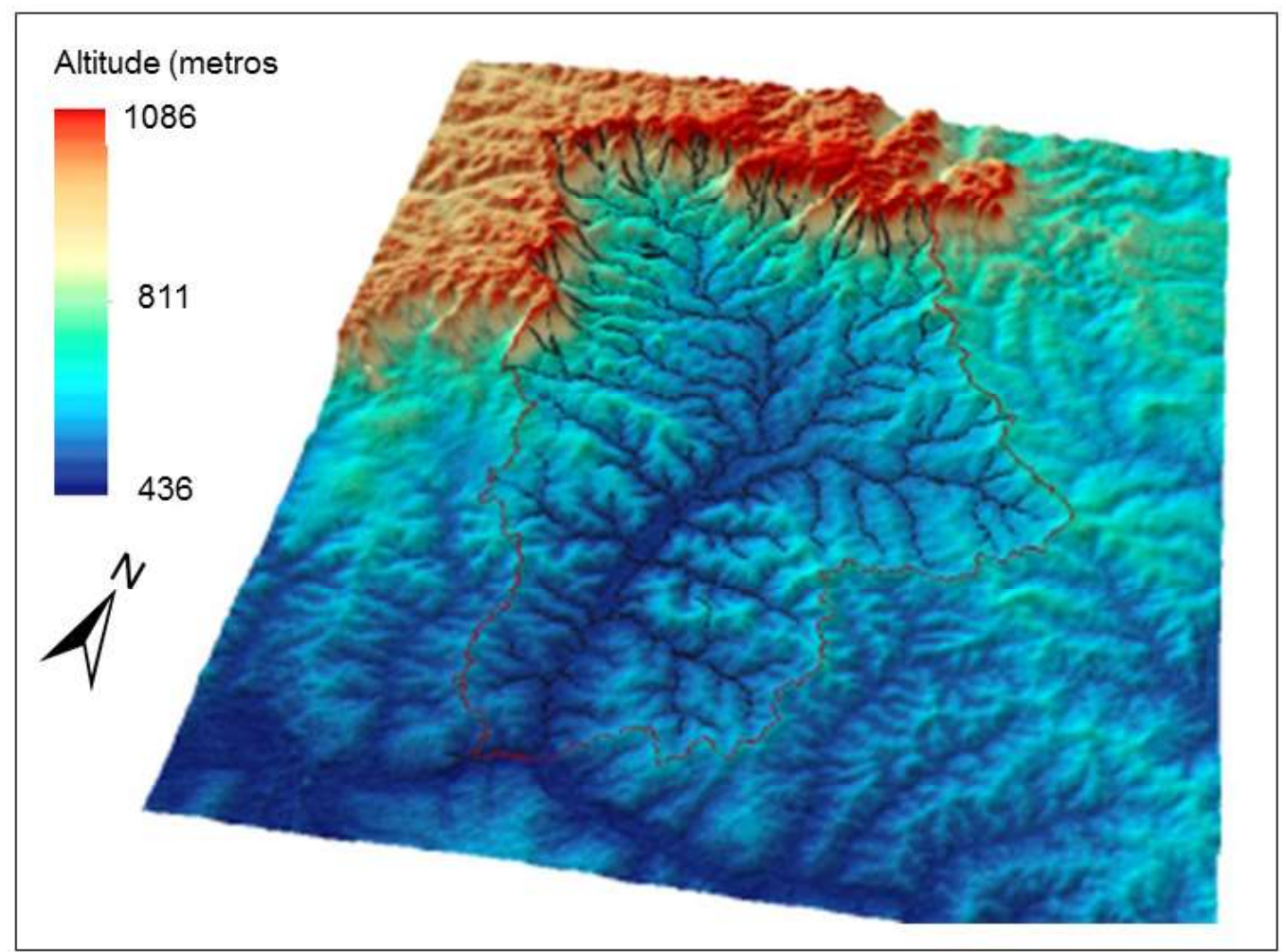

Figura 7 - Modelo em tridimensional da bacia do Ribeirão Araquá e áreas adjacentes. Elaborado a partir do raster Gdem Aster (2014). Elaboração: Autores, 2016 
Os processos estruturais que se estabeleceram, em conjunto com àqueles vinculados à morfoescultura, possibilitaram a espacialização de coberturas superficiais em posições topográficas mais rebaixadas. Oppenheim e Mallamphy (1936) e Facincani (2000) abordam que falhas com movimentações verticais, foram responsáveis pelo abatimento de blocos da margem esquerda do Ribeirão Araquá em sentido a margem direita. Provavelmente, esses eventos exerceram grande importância na configuração da rede de drenagem local e regional, sendo as evidências desses eventos encontradas em níveis de alto terraços, como abordam Souza e Perez Filho (2016a).

Os autores apontam que as principais evidências dos ajustes neotectônicos relacionados ao abatimento dos blocos na direção E-O, estão nas linhas de cascalhos Pleistocênicos presentes nos altos terraços, sobretudo referente a amostra AT-1(59.550 \pm 9.260 AP). Assim, mudanças na energia hidrodinâmica controlada pela rápida alteração dos níveis de bases durante o Pleistoceno (AT-1) e na transição Pleistoceno-Holoceno (AT-2), ocasionaram além da reorganização na rede de drenagem, a gênese de linhas de cascalhos embutidos (Souza e Perez Filho, 2016a).

Além disso, também são observadas na área anomalias de drenagem relacionadas à desvios abruptos, evidências de capturas de drenagem e trechos retilíneos. Essas anomalias sugerem controles expressivos por falhamentos, os quais devem ter sido reativados durante os eventos neotectônicos supracitados. Deste modo, o abatimento de blocos verificados por Oppenheim e Mallamphy (1936), Facincani (2000) e Souza e Perez Filho (2016a) deve ter conduzido a uma reorganização significativa da rede de drenagem, resultando na intensificação da erosão em setores da margem direita, na desarticulação de coberturas superficiais vinculadas aos pedimentos, terraços e superfícies de aplainamento, assim como no desenvolvimento de facetas triangulares nas encostas das escarpas da Serra de São Pedro e Itaqueri.

Sendo assim, após os eventos estruturais que contribuíram para a subsidência da bacia e elaboração do AT1, processos morfoesculturais conduziram à espacialização de coberturas superficiais em topos altimetricamente próximos aos 600 metros e, posteriormente, ao retrabalhamento desse material em altitudes próximas a dos altos terraços. Com a consequente evolução da rede de drenagem após 8.100 $\pm 820 \mathrm{AP}$, houve o desmantelado dessas coberturas, sobretudo na margem direita do Ribeirão Araquá, fazendo com que as amostras coletadas sobre a Superfície Urucaia correspondam aos remanescentes dos processos erosivos-deposicionais ocorridos a cerca de 12.000 AP. Em contrapartida, como consequência direta da migração do rio principal, na margem direita as coberturas superficiais ficaram melhor preservadas.

Registros de ajuste na rede de drenagem durante o Holoceno Inferior, também podem ser encontrados em um nível de baixo terraço (BT1). Por meio da datação absoluta obteve-se a idade de $9.850 \pm 1.120$ para o nível de baixo terraço mais elevado em relação a superfície da água (cerca de 5 metros), demonstrando que o vale do Ribeirão Araquá já se encontrava próximo da atual posição geográfica no início do Holoceno.

\subsection{Dinâmica geomorfológica das coberturas superficiais durante o Holoceno Superior}

Durante o Holoceno Superior a dinâmica erosivodeposicional das coberturas superficiais na bacia do Ribeirão Araquá está registrada em dois níveis de baixos terraços fluviais (terraços aluviais), localizados a 3 metros (BT2) e 2 metros (BT3) acima da superfície da água. Os resultados das datações absolutas sugerem a ocorrência de períodos deposicionais vinculados a ciclos de curta duração e relacionados às fases de estabilidades e instabilidades no sistema (Vandenberghe, 2015). As relações entre eventos deposicionais com oscilações climáticas holocênicas tem sido debatida na Europa por Macklin e Lewin (2008), Macklin et al. (2010), Macklin et al. (2013) e na Depressão Periférica Paulista por Storani e Perez Filho (2015), Souza e Perez Filho (2016) e Dias e Perez Filho (2016), cujos resultados apresentam uma importante correspondência com a área estudada.

Deste modo, Macklin et al. (2013) mostrou que os episódios de entrincheiramento em rios do Reino Unido, além de terem contribuído com periódicas reorganizações do sistema fluvial, também apresentam relações com eventos hidrológicos extremos, os quais estariam associados a ciclos climáticos de duração relativamente curta e ocorridos durante o Holoceno Superior. As idades absolutas obtidas por LOE das amostras coletadas na bacia do Ribeirão Araquá, apresentam correspondência com essas questões e sugerem que o primeiro ciclo deposicional ocorreu por volta dos $2.780 \pm 410 \mathrm{AP}$ (BT2), seguido por um novo período a $1.481 \pm 215 \mathrm{AP}$. 
Wanner et al (2011) aponta que no período que se estende de $2.600 \mathrm{AP}$ a $2.800 \mathrm{AP}$, ocorreram na região sudeste ambientes similares aos atuais. Afirmação que é corroborada com os estudos de Behling (2002), Gouveia et al. (2002), Scheel-Ybert et al. (2003) e Flantua et al. (2016), os quais indicam que a partir dos 3.000 A.P. são estabelecidas condições mais úmidas similares ao presente no estado de São Paulo. Entretanto, a granulométrica arenosa indicaria fluxos mais energéticos vinculados a menor umidade no sistema, provavelmente resultante de pulsações climáticas e erosivo-deposicionais correspondentes aos Ciclos de Bond (Bond et al, 1997), além da erosão de litologias sedimentares da Formação Piramboia. De qualquer modo, o baixo terraço BT2 deve ter sido elaborado em um ambiente com menos umidade do que atualmente, o que contribuiu para a elaboração de coberturas superficiais arenosas.

As coberturas superficiais presentes no nível de baixo terraço BT3 indicam a ocorrência de um evento erosivo-deposicional por volta dos $1.481 \pm 215$ AP. De acordo com Wanner et al. (2011) e Scheel-Ybert et al (2003), esse período é caracterizado por anomalias negativas de temperatura e umidade na região sudeste, principalmente no estado de São Paulo, de modo que características úmidas similares ao presente apareceram apenas a partir dos $1.000 \mathrm{AP}$, provavelmente em decorrência do término da Little Ice Age.

Deste modo, embora as análises granulométricas do terraço BT3 apontem para um ambiente deposicional menos energético (Franco-Argilosa) em relação a amostra BT2, quando observado o desvio padrão da idade absoluta ( \pm 215 anos), é possível situar o evento deposicional no final da Pequena Idade do Gelo e início do Período de Aquecimento Medieval (Wanner et al. 2011), o que poderia explicar as características discordantes entre as análises granulométricas e os trabalhos anteriores.

O início do atual período deposicional está registrado em aluviões localizados nas planícies de inundações, as quais apresentam idades de $600 \pm 135 \mathrm{AP}$ a 110 centímetros de profundidade e $300 \pm 50 \mathrm{AP}$ a 70 centímetros; situando ambas amostras na transição entre o Dark Age Cold e o início das características ambientais úmidas atuais (Wanner et al. 2011). Interessante observar que em ambas as profundidades, as análises granulométricas apontam para textura mais arenosa, sugerindo transporte relativamente energético.
Nesse sentido, embora Bridgland e Westaway (2008) afirmem que em condições quentes-úmidas predominem transportes de frações mais finas (silte e argila), é provável que haja nas coberturas superficiais do Ribeirão Araquá importante contribuição das litologias sedimentares que apresentam significativa erodibilidade.

Assim, embora as características granulométricas não possibilitem determinar com precisão as características do ambiente deposicional, assim como aspectos vinculados ao transporte dessas coberturas; é provável que a gênese dos aluviões estejam relacionadas a retomada da umidade durante o Holoceno Superior, afirmação que também é corroborada com os trabalhos de Pessenda et al. (2010), Wanner et al. (2011). Pessenda et al (2010), identificou na região do Vale do Ribeira (sul do estado de São Paulo) transformações ambientais no ultimo milênio, as quais, segundo os autores, resultariam do aumento da temperatura e umidade no período correspondente às datações das coberturas no Ribeirão Araquá.

Observa-se que a partir dos 8.000 AP oscilações climáticas tornaram-se mais recorrentes, permitindo o estabelecimento de processos erosivos-deposicionais com características distintas e, consequentemente, na elaboração de diferentes níveis de baixos terraços. Essa ciclicidade nos padrões de frequência, duração e intensidade dos eventos ambientais responsáveis pela organização do sistema fluvial estudado, apresentam relações cronológicas com a complexa dinâmica indicada por Bond et al. $(1997 ; 2001)$.

Bond et al. $(1997 ; 2001)$, aponta a ocorrência de 6 fases de resfriamento ao longo dos últimos 10 mil anos, sendo eles: 1) 8.300 - 8.100 AP; 2) 6.400 - $6.200 \mathrm{AP}$; 3) $4.800-4.600 \mathrm{AP}$; 4) $2.800-2.600 \mathrm{AP}$; 5) $1.650-1.450$ AP; 6) 650 - 450 AP. Os resultados das datações por Luminescência Opticamente Estimulada das coberturas superficiais dos baixos terraços e aluviões recentes, além de apontarem para uma importante correspondência com os 3 últimos eventos, sugerem que esses ciclos climáticos globais também tiveram grande impacto em ambientes tropicais úmidos.

\section{Conclusão}

Os resultados alcançados por meio das metodologias utilizadas possibilitaram avaliar a importância dos ajustes neotectônicos pleistocênicos na deformação das superfícies neogênicas e, consequentemente, na 
conformação de patamares altimétricos que viriam a receber os resultados dos processos morfoesculturais do Pleistoceno Superior e do retrabalhamento de coberturas superficiais no Holoceno Inferior.

A configuração altimétrica posterior ao rearranjo topográfico da bacia, também possibilitou a espacialização de coberturas superficiais mais recentes na mesma cota altimétrica das coberturas mais antigas. Deste modo, o estudo geocronológico das coberturas superficiais contribuiu para a compreensão da complexa dinâmica geomorfológica relacionada aos processos erosivos-deposicionais quaternários.

Também por meio das datações absolutas, análises físicas e morfológicas das coberturas superficiais, verificou-se o estabelecimento de diferentes ambientes deposicionais em períodos que se relacionam com as alternâncias climáticas em escalas globais. Os ambientes estabelecidos no Pleistoceno Superior e Holoceno Inferior provavelmente ocorreram em consonância com o aumento da umidade decorrente do término do Último Máximo Glacial, mas que ainda foram menos úmidas do que as condições ambientais hodiernas.

No âmbito do Holoceno Superior, as coberturas superficiais em diferentes níveis de terraços indicam registros de ajustes ambientais associados a curtos ciclos climáticos, os quais também são verificados em outras partes do globo. Deste modo, os processos relacionados à elaboração dos níveis de baixos terraços, bem como dos aluviões presentes na bacia do Ribeirão Araquá, provavelmente estão vinculados a essas pulsações climáticas holocênicas, as quais possibilitaram uma dinâmica de alterações hidrodinâmicas ao longo do Holoceno Superior.

\section{Agradecimentos}

Os autores agradecem à Fundação de Amparo à Pesquisa do Estado de São Paulo (FAPESP) pelo suporte financeiro por meio do Auxílio Regular (Processos Fapesp: 2012/00145-6) e da bolsa de mestrado (Processo 2014/03894-5).

\section{Referências Bibliográficas}

AB'SABER, A. N. Superfícies Fósseis em Processo de Exumação no Estado de São Paulo. Revista da Universidade de Campinas, v. 3, n. 8-9, p. 79-92, 1955.
AB'SABER, A. N. Depressão Periférica: um setor de áreas de circundenudação pós-cretácica na Bacia do Paraná. Geomorfologia. São Paulo, v. 15, p. 1-26, 1969.

ADAMS, G. Planation Surfaces: Peneplains, Pediplains, and Etchplains. v. 22. Dowden, Hutchigon \& Ross, Inc., Strondsburg, 1975. 492 p.

ALMEIDA, F. F. M. O Planalto Basáltico da Bacia do Paraná. Boletim Paulista de Geografia, v. 24, p. 03-34, 1956.

ALMEIDA, F. F.M. Fundamentos geológicos do relevo paulista. Boletim IGC, São Paulo, n. 41, 1964.

ALMEIDA, F. F. M; HASUI, Y; NEVES, B.B.B; FUCK, R. A. Brazilian structural provinces: an introduction. Earth Science Review, v. 17, ed. 1-2, 1-29, 1981.

ALMEIDA, F. F. M. Relevo de Cuesta na bacia sedimentar do Rio Paraná. Boletim Paulista de Geografia, São Paulo, n. 3, p. 21-33, 1949.

ALMEIDA, F. F. M; CARNEIRO, C. D. R. Inundações marinhas fanerozóicas no Brasil e recursos minerais associados. In: MANTESSO NETO, V.; BARTORELLI, A.; CARNEIRO, C. D. R.; BRITO-NEVES, B. B. (Org.). Geologia do Continente SulAmericano: Evolução da obra de Fernando Flávio Marques de Almeida. 1 ed., v. 1, p. 43-58, 2004.

ARRUDA, E. M. Contribuição da dinâmica morfoestrutural e morfoescultural na estruturação da bacia do Ribeirão Entupido, Complexo Alcalino do Passa Quatro-SP. Tese (Doutorado em Geografia). Instituto de Geociências e Ciências Exatas, Universidade Estadual Paulista, Rio Claro. 2008. 458p.

BARRETO, M. M. R. Geomorfologia da Área de São Pedro (SP). Notícia Geomorfológica, Campinas, v. 10, n. 19, p. $47-61,1970$.

BEHLING, H. A high resolution Holocene pollen record from Lago Pires, SE Brazil: vegetation, climate and fire history. Journal of Paleolimnology. v. 14, p. 253-268, 1995.

BEHLING, H. South and southeast Brazilian grasslands during Late Quaternary times: a synthesis. Palaeogeography, Palaeoclimatology, Palaeoecology, v. 177, p. 19-27, 2002.

BIGARElla, J. J.; MOUSINHO, M. R.; SILVA, J. X. Pediplanos, pedimentos e seus depósitos correlativos no Brasil. Boletim Paranaense de Geografia. Curitiba, n.16/17, p 117151, 1965.

BIGARELLA, J. J.; BECKER, R. D.; SANTOS, G. F. Estrutura e origem das paisagens tropicais e subtropicais. $2^{\mathrm{a}}$ ed. Florianópolis: Editora da UFSC, v. 3. 2009. 1436p. 
BISHOP, P. Long-term landscape evolution: linking tectonics and surface processes. Earth, Surface, Process and Landforms, v. 32, p. 329-365, 2007.

BJÖRNBERG, A. J. S. Sedimentos pós-cretácicos do leste do Estado de São Paulo. Tese (livre docência), Escola de Engenharia de São Carlos, Universidade de São Paulo, São Carlos-SP. 1965. 132p.

BJÖRNBERG, A. J. S; LANDIM, P.M.B. Contribuição ao estudo da formação Rio Claro (Neocenozóico). Boletim Sociedade Brasileira de Geologia. São Paulo, v. 15, n. 4, p. 43-67, 1966.

BOND, G.; SHOWERS, W.; CHESEBY, M.; LOTTI, R.; ALMASI, P.; DE MENOCAL, P.; PRIORE, P.; CULLEN, H.; HAJDAS, I.; BONANI, G. A pervasive millennialscale cycle in the North Atlantic Holocene and glacial climates. Science, v. 294, p. 2130-2136, 1997.

BOND, G.; KROMER, B.; BEER, J.; MUSCHELER, R.; EVANS, M.N.; SHOWERS, W.; HOFFMANN, S.; LOTTIBOND, R.; HAJDAS, I.; BONANI, G. Persistent solar influence on North Atlantic climate during the Holocene. Science, v. 278, p. 1257-1266, 2001.

BRIDGLAND, D. R.; WESTAWAY, R. Climatically controlled river terrace staircases: a worldwide Quaternary phenomenon. Geomorphology, v. 98, p. 285-315, 2008.

BULLOCK, P.; FEDOROFF, N.; JONGERIUS, A.; STOOPS, G.; TURSINA, T. Handbook for Soil Thin Section Description. Wolverhampton: Waine Research Publications, 1985, 152p.

CAMARGO, A. O.; MONIZ,A. C.; JORGE, J.A.; VALADARES, J. M. A. S. Métodos de análise química, mineralógica e física do Instituto Agronômico de Campinas. Campinas: Instituto Agronômico, 94p, 1968.

CHRISTOFOLETTI, A. Geomorfologia Fluvial. Edgar Blucher Ltda, v. 1, 313p. 1981.

CORDIER, S. Optically stimulated luminescence dating: procedures and applications to geomorphological research in France. Geomorphologie: relief, processos, environnement, vol. 16, n.1, p.21-40, 2010.

CORRÊA, A.C.B. Dinâmica geomorfológica dos compartimentos elevados do Planalto da Borborema, Nordeste do Brasil. Tese (Doutorado em Geografia), Instituto de Geociências e Ciências Exatas, Universidade Estadual Paulista, Rio Claro. 2001. 386p.

CORREA, A. C. B.; ESPÍNDOLA, C. R; MENDES, I. A. Avaliação da dinâmica geomorfológica dos compartimentos elevados do Planalto da Borborema, Nordeste do Brasil, com base no método de datação da (LOE) Luminescência Opticamente Estimulada. In: MENDES, I. A.; GERARDI, L. O. (Org.). Do natural, do Social e de suas interações. São Paulo, p. 21-34, 2002.

CORRÊA, A. C. B.; MENDES, I. A. O problema das superfícies de erosão: novas abordagens conceituais e metodológicas. Revista de Geografia, v. 18(2), p. 70- 86, 2002.

DIAS, R. L.; PEREZ FILHO, A. Ambientes deposicionais neocenozoicos nas superfícies de aplainamento na Depressão Periférica Paulista. Revista Geonorte, v. 10, p. 66-71, 2014.

DIAS, R. L.; PEREZ FILHO, A. Geocronologia de terraços fluviais na bacia hidrográfica do rio Corumbataí-SP a partir de Luminescência Opticamente Estimulada (LOE). Revista Brasileira de Geomorfologia, v. 16, p. 341-349, 2015.

DIAS, R. L.; PEREZ FILHO, A. Evolução das coberturas superficiais holocênicas em baixos terraços fluviais da bacia do rio Corumbataí - SP por meio de datação absoluta por Luminescência Opticamente Estimulada (LOE). Geografia (Impresso), v. 41, p. 419-428, 2016.

DOS SANTOS, M.; LADEIRA, F. S. B. Tectonismo em perfís de alteração da Serra de Itaqueri (SP): análise através de indicadores cinemáticos de falhas. Geociências (São Paulo), v. 25, n. 1, p. 135-149, 2007.

ETCHEBEHERE, M.L; SAAD, A.R; FULFARO, V.J; PERINOTTO, J.A.J. Aplicação do Índice "Relação DeclividadeExtensão - RDE" na Bacia do Rio do Peixe (SP) para detecção de deformações Neotectônicas. Revista do Instituto de Geociências - USP, v. 4, n. 2, p. 43-56, 2004.

FACINCANI, E.M. Morfotectônica da depressão periférica paulista, cuesta basáltica e planalto interior: Regiões de São Carlos, Rio Claro e Piracicaba-SP. Tese (Doutorado em Geociências), Instituto de Geociências e Ciências Exatas, Universidade Estadual Paulista Júlio de Mesquita Filho, Rio Claro-SP. 2000. 222p.

FLANTUA, S. G. A., HOOGHIEMSTRA, H., VUILLE, M., BEHLING, H., CARSON, J. F., GOSLING, W. D., HOYOS, I.; M. P.; MONTOYA, E.; MAYLE, F.; MALDONADO, A.; RULL, V.; TONELLO, M. S.; WHITNEY, B. S.; GONZÁLEZARANGO, C. Climate variability and human impact in South America during the last 2000 years: synthesis and perspectives from pollen records. Climate of the Past, v. 12(2), p. 483-523, 2016.

GOUVEIA, S. E. M.; PESSENDA, L. C. R.; ARAVENA, R.; BOULET, R.; SCHEEL-YBERT, R.; BENDASSOLI, J. A.; RIBEIRO, A.S.; FREITAS, H. A. Carbon isotopes in charcoal 
and soils in studies of paleovegetation and climate changes during the late Pleistocene and the Holocene in the southeast and centerwest regions of Brazil. Global and Planetary Change, v. 33, p. 95-106, 2002.

HUNTLEY, D. J.; GODFREY-SMITH, D. I.; THEWALT, M. L. W. Optical dating of sediments. Nature, v. 313, p. 105-107, 1985.

IAC (1989) Carta Pedológica Semi-Detalhada do Estado de São Paulo- 1:100.000, Folha Piracicaba-SP. Publicação Instituto Geográfico e Cartográfico (IGC), 1989.

LEOPOLD, L. B., WOLMAN, M. G., MILLER, J. P. Fluvial processes in geomorphology. W. H. Freeman and Company, San Francisco, California. 1964. 544p.

MACKLIN, M. G; JONES, A. F; LEWIN, J. River response to rapid Holocene environmental change: evidence and explanation in British catchments. Quaternary Science Reviews, v. 29, p. 1555-1576, 2010.

MACKLIN, M. G.; LEWIN. J.; JONES, A. F. River entrenchment and terrace formation in the UK Holocene. Quaternary Science Reviews, v. 76, p. 194-206, 2013.

MACKLIN, M. G.; LEWIN, J. Alluvial responses to the changing Earth System. Earth Surface, Processes and Landforms, v, 33, p. 1374-1395, 2008.

MARTONNE, E. Problemas morfológicos do Brasil tropical atlântico. Revista Brasileira de Geografia. Rio de Janeiro, ano 1, n. 4, p. 523-550, 1943.

MASSOLI, M. Geologia da folha de Santa Rita do Passa Quatro. Revista do Instituto de Geociências, v. 1 (1), p.7-13, 1980.

MAYEWSKI, P. A.; ROHLING, E. E.; STAGER, J. C.; KARLEN, W.; MAASCH, K. A.; MEEKER, L. D.; MEYERSON, E. A.; GASSE, F.; VAN KREVELD, S.; HOLMGREN, K.; LEETHORP, J.; ROSQVIST, G.; RACK, F.; STAUBWASSER, M.; SCHNEIDER, R.R.; STEIG, E. J. Holocene climate variability. Quaternary Research, v. 62, p. 243-255, 2004.

MELO, M. S. A. A Formação Rio Claro e depósitos associados: sedimentação Neocenozoica na depressão periférica paulista. Tese (Doutorado em Geologia Sedimentar), Instituto de Geociências, Universidade de São Paulo, São Paulo. 1995. doi:10.11606/T.44.1995.tde-22062015-130942.

MODENESI, M.C. Contribuição à geomorfologia da região de Itu-Salto: estudo de formações superficiais. Série Teses e Monografias, Instituto de Geografia-USP, São Paulo, v. 10. 1974. 99 p.

MOURA, J.R.S. e MELLO, C.L. Classificação aloestratigráfica do quaternário superior na região de Bananal (SP/RJ). Revista Brasileira de Geociências, v. 21(3), p. 236-254. 1991.

MURRAY, A.S.; WINTLE, A.G. Luminescence dating of quartz using an improved single-aliquot regenerative-dose protocol. Radiation Measurements, v. 32 (1), p. 57-73, 2000.

NOVAES PINTO, M. Aplainamento nos trópicos: uma revisão conceitual. Geografia. Rio Claro, v. 13(26), p. 119-129, 1988.

OLIVEIRA, J. B.; JACOMINE, P. K. T.; CAMARGO, M. N. Classes gerais de solos do Brasil: guia auxiliar para o seu reconhecimento. FUNDUNESP: Jaboticabal-SP. 201p. 1992.

OLIVEIRA, D. Estudo da origem dos materiais dos solos da cobertura arenosa do glacis de São Pedro, em São Pedro, SP. Trabalho de Graduação Individual, Departamento de Geografia, Faculdade de Filosofia, Letras e Ciências Humanas, Universidade de São Paulo. 1992. 75p.

OPPENHEIM, V.; MALAMPHY, M. Sobre a Tectónica da Área de São Pedro - Xarqueada. Avulso do Serv. Fom. Prod. Mineral do Min. Agricultura, v. 7, p. 1-15, 1936.

ORTiZ-JAUREguizAR, E.; CLADERA, G. A. Paleoenvironmental evolution of southern South America during the Cenozoic. Journal of Arid Environmental, v. 66, p. 498-532, 2006.

PEIXOTO, C. A. B; THEODOROVICZ, A. GeodiversidadeSP. Disponível em: GATESP-SGB $\backslash C \$ S I G \_S P \backslash G e o d i v e r s i d a d e \backslash$ Geodiversidade_SP.shp. 2009.

PENTEADO, M.M. Geomorfologia do setor centroocidental da Depressão Periférica Paulista. Tese (Doutorado em Geografia), Faculdade de Filosofia, Ciências e Letras, Universidade Estadual Paulista, Rio Claro, 1968a, 86p.

PENTEADO, M. M. Implicações tectônicas na gênese das cuestas da bacia de Rio Claro (SP). Notícia Geomorfológica, Campinas, v. 8, n. 15, p. 19-41. 1968 b.

PEREZ FILHO, A.; DONZELLI, J.L; LEPSCH, I.F. Relação Solos-Geomorfologia em Várzea Do Rio Moji-Guaçu (SP). Revista Brasileira de Ciência do Solo, Viçosa, v. 4, p.181187, 1980.

PESSENDA, L. C. R; SAIA, S. E. M. G; GOUVEIA, S. E. M; LEDRU, M. P; SIFEDDINE, A.; AMARAL, P. G. C; BENDASSOLLI, J. A. Last millennium environmental changes and climate inferences in the Southeastern Atlantic forest, Brazil. Anais da Academia Brasileira de Ciências (Impresso), v. 82, p. 717-729, 2010.

PINHEIRO, M. R; QUEIROZ NETO, J. P. Reflexões sobre a 
gênese da Depressão Periférica Paulista: o exemplo da região da Serra de São Pedro e do Baixo Piracicaba, SP. Revista do Instituto Geológico, São Paulo, v. 35, n. 1, p. 47-59, 2014.

PINHEIRO, M. R; QUEIROZ NETO, J.P. Neotectônica e evolução do relevo da região da Serra de São Pedro e do baixo Piracicaba/Sudeste do Brasil. Revista Brasileira de Geomorfologia, v. 16, p. 593-613, 2015.

PONÇANO, W.L; ALMEIDA, F.F.M. Superfícies erosivas nos planaltos cristalinos do Leste paulista e adjacências: uma revisão. Cadernos IG/Unicamp, v.3, n.1., 1993.

PYE, K; TSOAR, H. Aeolian sand and sand dunes. London, Unwin Hyman. 1990. 369p.

QUEIROZ NETO, J.P; JOURNAUX, A. Carta geomorfológica de São Pedro-SP: Sedimentologia e Pedologia. Instituto de Geografia - USP, v. 12, p. 1-33, 1978.

QUEIROZ NETO J P. O estudo de formações superficiais no Brasil. Revista do Instituto Geológico, v. 22, n. 1-2. 2001.

RICCOMINI C. Considerações sobre a posição estratigráfica e tectonismo deformador da Formação Itaqueri na porção centroleste do Estado de São Paulo. Revista do Instituto Geológico, v. 18, p. $41-48,1997$.

SALGADO, A.A.R. Superfícies de Aplainamento: Antigos paradigmas revistos pela ótica dos novos conhecimentos geomorfológicos. Geografias (UFMG), v. 3, p. 64-78, 2007.

SALGADO-LABOURIAU, M. L; BARBERI, M; FERRAZVICENTINI, K.R. A dry climatic event during the Late Quaternary of tropical Brazil. Review of Paleobotany and Palynology, v. 99, p. 115-129, 1998.

SALLUN, A. E; SUGUIO, K; TATUMI, S. H; YEE, M; SANTOS, J; BARRETO, A. M. F. Datação absoluta de depósitos quaternários brasileiros por luminescência. Revista Brasileira de Geociências, v. 37(2), p. 402-413, 2007.

SCHEEL-YBERT, R. Vegetation stability in the southeastern Brazilian coastal area from 5500 to 1400 14C yr BP deduced from charcoal analysis. Review of Palaeobotany and Palynology, v. 110, p. 111-138, 2000.

SCHEEL-YBERT, R.; GOUVEIA, S.E.M.; PESSENDA, L.C.R.; ARAVENA, R.; COUTINHO, L.M.; BOULET, R. Holocene palaeoenvironmental evolution in the São Paulo State (Brazil), based on anthracology and soil $13 \mathrm{C}$ analysis. The Holocene, v. 13, p. 73-81, 2003.

SILVA, T. M. Superfícies Geomorfológicas do Planalto Sudeste Brasileiro: Revisão teórico-conceitual. Geo Uerj. Ano 11, v.3, n.20, p.1-22, 2009.

SOUSA, M. O. L. Evolução tectônica dos altos estruturais de Pitanga, Artemis, Pau d'alho e Jiboia: centro do estado de São Paulo. Tese (Doutorado em Geociências), Programa de pós-graduação em Geociência, Universidade Estadual Paulista, Rio Claro. 2002. 202p.

SOUZA, M. M.; BRANCO, F. R.; JASPER, A.; PESSENDA, L. C. R. Evolução paleoambiental holocênica da porção nordeste do Estado de São Paulo, Brasil. Revista Brasileira de Paleontologia, v. 16, p. 297-308, 2013.

SOUZA, A. O.; PEREZ FILHO, A. Mudanças na dinâmica fluvial da bacia hidrográfica do ribeirão Araquá: eventos tectônicos e climáticos no Quaternário. Geousp - Espaço e Tempo (Online), v. 20, n. 3, p. 636-656, 2016a. ISSN 2179-0892.

SOUZA, A. O.; PEREZ FILHO, A. (2016b). Holoceno Superior na Depressão Periférica Paulista: Registros de flutuações climáticas de curta duração em baixos terraços fluviais do estado de São Paulo, Brasil. In: VIEIRA, A.; GONÇALVES, A. B.; COSTA, F.; CUNHA, L.; TROLEIS, A. L. (Org.). A Geografia Física e a gestão de territórios resilientes e sustentáveis. 1ed. Minho: Universidade do Minho, v. 1, p. 331-339.

STEVAUX, J. C. Climatic events during the Late Pleistocene and Holocene in the Upper Parana River: Correlation with NE Argentina and South-Central Brazil. Quaternary International, v. 72, p. 73-86, 2000.

STORANI, D.L; PEREZ FILHO, A. Novas informações sobre geocronologia em níveis de baixo terraço fluvial do rio Mogi Guaçu, SP, Brasil. Revista Brasileira de Geomorfologia, v. 16, p. 191-199, 2015.

STORANI, D. Cenário regional das oscilações climáticas quaternárias: baixos terraços fluviais no contexto da Depressão Periférica e do Planalto Ocidental Paulista. Tese (doutorado), Instituto de Geociências, Universidade Estadual de Campinas-SP. 2015. 256 p.

SUGUIO, K. (2000). As mudanças paleoclimáticas da Terra e seus registros, com ênfase no Quaternário. In: Sant'Anna Neto (org.). Variablidade e mudanças climáticas: implicações ambientais e socioeconômicas. Maringá: Eduem. 259 p.

VALÉZIO, E. V. Dinâmica antrópica no canal fluvial do Córrego Tucum - São Pedro, São Paulo (Brasil). Revista Brasileira de Geomorfologia, v. 16, n. 4, 2015.

THOMAS, M. Understanding the impacts of Late Quaternary climate change in tropical and sub-tropical regions. Geomorphology. 101, p.146-158, 2008. 
THOMAS, M.; THORP, M. B. Geomorphic response to rapid climatic and hydrologic change during the late Pleistocene and Early Holocene in the humid and sub-humid tropics. Quaternary Science Reviews, v. 14, p. 193-207, 1995.

TUCKER, M. (ed.). Techniques in Sedimentology. Blackwell Science. 1995. 394 p.

USDA. Soil Survey Division Staff. Soil survey manual. Agriculture handbook, v. 18, 1993, 437p.

VANDENBERGHE, J. The relation between climate and river processes, landforms and deposits during the Quaternary. Quaternary International, v. 91, n. 1, p. 17-23, 2002.

VANDENBERGHE, J. River terraces as a response to climatic forcing: formation processes, sedimentary characteristics and sites for human occupation. Quaternary International, v. 370, p. 3-11, 2015.

WANNER, H.; SOLOMINA, O., GROSJEAN, M.; RITZ, S. P.; JETEL, M. Structure and origin of Holocene cold events. Quaternary Science Reviews, v. 30(21), p. 3109-3123, 2011. 